\title{
Descending Systems Direct Development of Key Spinal Motor Circuits
}

\author{
Calvin C. Smith, ${ }^{1}$ Julian F.R. Paton, ${ }^{2}$ CSamit Chakrabarty, ${ }^{1}$ and ${ }^{\circ}$ Ronaldo M. Ichiyama ${ }^{1}$ \\ ${ }^{1}$ School of Biomedical Sciences, University of Leeds, Leeds LS2 9JT, United Kingdom, and ${ }^{2}$ Department of Physiology, School of Medical Sciences, \\ University of Bristol, Bristol BS8 1TH, United Kingdom
}

The formation of mature spinal motor circuits is dependent on both activity-dependent and independent mechanisms during postnatal development. During this time, reorganization and refinement of spinal sensorimotor circuits occurs as supraspinal projections are integrated. However, specific features of postnatal spinal circuit development remain poorly understood. This study provides the first detailed characterization of rat spinal sensorimotor circuit development in the presence and absence of descending systems. We show that the development of proprioceptive afferent input to motoneurons (MNs) and Renshaw cells (RCs) is disrupted by thoracic spinal cord transection at postnatal day 5 (P5TX). P5TX also led to malformation of GABApre neuron axo-axonic contacts on Ia afferents and of the recurrent inhibitory circuit between MNs and RCs. Using a novel in situ perfused preparation for studying motor control, we show that malformation of these spinal circuits leads to hyperexcitability of the monosynaptic reflex. Our results demonstrate that removing descending input severely disrupts the development of spinal circuits and identifies key mechanisms contributing to motor dysfunction in conditions such as cerebral palsy and spinal cord injury.

Key words: GABApre neurons; plasticity; proprioceptive afferents; Renshaw cells; sensorimotor; spinal cord

\section{Significance Statement}

Acquisition of mature behavior during postnatal development correlates with the arrival and maturation of supraspinal projections to the spinal cord. However, we know little about the role that descending systems play in the maturation of spinal circuits. Here, we characterize postnatal development of key spinal microcircuits in the presence and absence of descending systems. We show that formation of these circuits is abnormal after early (postnatal day 5 ) removal of descending systems, inducing hyperexcitability of the monosynaptic reflex. The study is a detailed characterization of spinal circuit development elucidating how these mechanisms contribute to motor dysfunction in conditions such as cerebral palsy and spinal cord injury. Understanding these circuits is crucial to developing new therapeutics and improving existing ones in such conditions.

\section{Introduction}

In most mammals, mature overground locomotion is acquired throughout postnatal development despite the early emergence of functioning brainstem and spinal locomotor circuits (Cazalets et al., 1990; Van Hartesveldt et al., 1991; Ozaki et al., 1996). For example, in rats, quadrupedal locomotion is achieved at postnatal day 10 (P10)-P12, with a striking transition to motor maturity occurring at P14 (Altman and Sudarshan, 1975). By P21, locomotion is indistinguishable from that of adult animals. This protracted acquisition of overground locomotion is thought to

\footnotetext{
Received Jan. 17, 2017; revised May 10, 2017; accepted May 24, 2017.

Author contributions: C.C.S., J.F.R.P., S.C., and R.M.I. designed research; C.C.S. performed research; C.C.S. analyzed data; C.C.S., J.F.R.P., S.C., and R.M.I. wrote the paper.

The authors declare no competing financial interests.

Correspondence should be addressed to Calvin C. Smith, School of Biomedical Sciences, University of Leeds, Woodhouse Lane, Leeds LS2 9JT, UK. E-mail: calvin.smith@ucl.ac.uk.

DOI:10.1523/JNEUROSCI.0149-17.2017

Copyright $\odot 2017$ the authors $\quad 0270-6474 / 17 / 376372-16 \$ 15.00 / 0$
}

reflect activity-dependent mechanisms of motor circuit development as the animal begins to interact with its environment. For example, corticospinal tract (CST) terminations only reach the gray matter of caudal spinal segments at P9-P10, with innervation patterns maturing by $\mathrm{P} 14$, the same time as locomotion (Donatelle, 1977). Brainstem structures reach the lumbar spinal cord at or shortly after birth, but also undergo significant development during the first 2 weeks (Bregman, 1987; Brocard et al., 1999; Vinay et al., 2005).

Conversely, sensory systems make functional connections with their spinal targets prenatally, with reorganization and refinement taking place postnatally (Fitzgerald, 2005; Chakrabarty and Martin, 2011a). Proprioceptive Ia afferents (PAs) form functional monosynaptic connections with homonymous and synergistic motoneurons (MNs) at embryonic day 19 (E19) (Kudo and Yamada, 1985; Chen et al., 2003). This sensory-motor connectivity exhibits stringent specificity that is mainly dependent upon MN positional cues and cell surface signaling (Mears and Frank, 
1997; Sürmeli et al., 2011; Fukuhara et al., 2013). Although features such as sensory-motor fidelity appear hardwired, postnatal retraction of dense PA projections in the cervical cord is thought to depend on late integration of descending systems (Gibson and Clowry, 1999; Chakrabarty and Martin, 2011a). However, this profile has never been demonstrated in the lumbar spinal cord despite obvious functional differences, especially in fine motor control.

Functional deficits following neonatal injuries to descending systems highlight the importance of supraspinal projections to spinal sensorimotor circuit development. In cerebral palsy (CP), perinatal insults to the brain lead to debilitating spasticity resulting from aberrant growth and reduced modulation of sensory afferents (Dietz and Sinkjaer, 2007; Rosenbaum et al., 2014). Interestingly, sensory afferents also contribute to the remarkable recovery of locomotion seen after neonatal spinal transection in rodents (Weber and Stelzner, 1977; Commissiong and Toffano, 1989; Saunders et al., 1998; Petruska et al., 2007; Tillakaratne et al., 2010; Ichiyama et al., 2011). With locomotor training, prospects of functional recovery in neonatally transected animals far outweigh those of adult transected animals, suggesting that spinal circuits in the former are better able to use sensory information in the absence of supraspinal control. Indeed, although sensory afferents are important to recovery, Bui et al. (2016) show that an interposed sensorimotor microcircuit becomes indispensable after adult thoracic spinal cord transection (TX). It is vital, therefore, that we further understand the development of spinal sensorimotor circuits in normal and injured states.

Recently, important steps have been taken towards enhancing our understanding of development of specific spinal circuits. Siembab et al. (2016) genetically manipulated PA inputs in mice to demonstrate that maturation of motor axon inputs to RCs is dependent upon the strength of PA input during early postnatal development. In addition, Mendelsohn et al. (2015) showed that genetically blocking neurotransmission between PAs and MNs during development leads to increased PA projections to heteronymous (synergist) MNs.

In this study, we provide the first detailed characterization of spinal sensorimotor circuit development in the presence and absence of descending systems. We show that normal development of PA input to all regions of the spinal cord, including MNs and RCs, is disrupted after neonatal transection. This leads to malformation of microcircuits involved in recurrent inhibition of MNs and presynaptic inhibition of afferents. We used an in situ, perfused whole rat preparation to study physiological development of spinal motor circuits and show that a lack of descending input and resultant malformation of inhibitory microcircuits resulted in hyperexcitability of the monosynaptic reflex.

\section{Materials and Methods}

\section{Experiments}

Experiments and procedures were performed in a manner that conformed to the UK Home Office guidelines regarding the use of animals. Approval was granted by the local ethics committee (University of Leeds).

\section{Animals}

Both male and female Wistar rats were used for all experiments. The ages of assessment for both intact and TX rats were P10, P14, and P21. These ages were used because they represent significant behavioral milestones based on previous literature (Altman and Sudarshan, 1975; Westerga and Gramsbergen, 1993a, b). For example, at P10 (an immature time point), rats are capable of some quadrupedal weight bearing but locomotor abilities are minimal. At P14 (transition time point), there is a striking transition to adult-like locomotion with some deficits in speed and accuracy. At P21 (mature time point), overground locomotor kinematics are indistinguishable from the adults.

\section{Decerebrate perfused rat preparation}

Preparation setup. Wistar rats aged $\mathrm{P} 10-\mathrm{P} 21$ were weighed and then anesthetized with isoflurane $\left(95 \% \mathrm{O}_{2}, 5 \% \mathrm{CO}_{2}\right.$ mixture, 5\% induction, $2 \%$ maintenance) until loss of paw withdrawal. A midline laparotomy was performed and the stomach, spleen, and free intestine were ligated and removed. Once evisceration was complete, the animal was transferred to an ice bath containing artificial CSF (ACSF composition listed below) bubbled with carbogen gas $\left(95 \% \mathrm{O}_{2}, 5 \% \mathrm{CO}_{2}\right)$, a precollicular decerebration was performed, and the skin was removed. The animal was then transferred to a cold dissecting dish $\left(\mathrm{ACSF},<3^{\circ} \mathrm{C}\right)$, where a midline sternotomy permitted access to the chest cavity. Most of the lung parenchyma and thymus were removed for easy access to the heart. An incision was made into the apex of the heart for later insertion of the cannula (Ø $1.25 \mathrm{~mm}$, DLR-4; Braintree Scientific) before another small incision was made into the right atrium to allow draining of the perfusate. The animal was then transferred to the recording chamber and rested (supine) on a custom Sylgard (Dow-Corning) bed. The cannula was immediately inserted transcardially into the ascending aorta (Fig. 1A). The cannula was fixed in place using a single suture (no 2, silk; Mersilk). Once the cannula was secured, the animal was carefully transferred to the prone position and the flow rate was increased gradually over $1 \mathrm{~min}$ until further increases in flow failed to increase perfusion pressure $(\sim 40 \mathrm{mmHg})$. The pressures before and after turning the animal were compared to ensure the cannula had not retracted from the aorta.

The oxygenated perfusate was pumped from a flask to the preparation via a heat exchanger $\left(32^{\circ} \mathrm{C}\right)$, bubble traps, and a particle filter $(25 \mu \mathrm{m}$ screen; Millipore) (Fig. 1B). The flow was generated by a pump (Minipuls 3; Gilson) with the volume maintained at $200 \mathrm{ml}$. After initiation of flow, the heart resumed beating immediately and the preparation started to warm up. Successful perfusion was indicated by liver blanching, filling of the scull cavity, atrial distension, and spontaneous motor activity. Then, 100-200 pM vasopressin (Arg-8-Vasopressin, AVP; Abcam) was added to the perfusate to increase the systemic resistance and pressure to $50-80$ $\mathrm{mmHg}$, which has been deemed sufficient for adequate perfusion of the caudal spinal cord (Pickering and Paton, 2006). Respiratory contractions were observed once the pressure reached $40-50 \mathrm{mmHg}$, indicating brainstem viability (Fig. $2 A-C$ ). Lumbar spinal cord viability was initially observed by spontaneous rhythmic hindlimb movements and nociceptive reflexes in response to tail and hindlimb pinches (Fig. $2 D, E$ ). Once stimulation and recording equipment were in place, robust $\mathrm{H}$ reflex responses confirmed viability of the lumbar cord.

Solutions. Modified Ringer's solution (ACSF) containing the following (in mM): $125 \mathrm{NaCl}, 25 \mathrm{NaHCO}_{3}, 3 \mathrm{KCl}, 2.5 \mathrm{CaCl}_{2}, 1.25 \mathrm{MgSO}_{4}, 1.25$ $\mathrm{KH}_{2} \mathrm{PO}_{4}$, and 10 D-glucose was used. $\mathrm{A} \mathrm{pH}$ of 7.35-7.4 was attained once carbogenated. Polyethylene glycol $(1.25 \%)$ was added as an oncotic agent.

\section{H reflex}

Isolation of nerves. Once the cannula was secure and the animal was fixed in place using ear bars, a small incision was made into the fascia separating the quadriceps and hamstring muscles. Using blunt dissection, the muscles were reflected, the sciatic nerve carefully freed from surrounding tissue (apart from its insertion into gastrocnemius), and the tibial nerve located and mounted on a bipolar hook electrode (Fig. 3D).

Stimulation and recording methods. The nerve was stimulated via hook electrodes with a monophasic square pulse generated by an ISO-Flex isolated stimulator. Square pulses $(0.3 \mathrm{~ms})$ were generated using the A.M.P.I. Master- 8 to trigger the stimulator, allowing $5 \mathrm{~s}$ recovery between pulses. Evoked intramuscular responses were recorded using fine bipolar needle electrodes (SpesMedica) inserted into the gastrocnemius muscle. For each animal, graded stimulation of the nerve produced a recruitment curve that was used to determine Ia afferent and motor axon thresholds (Fig. $3 A-C$ ). The $\mathrm{H}$ reflex threshold was determined as the intensity at which the smallest visible response occurred at a frequency of $50 \%$. H reflexes on the ascending portion of the recruitment curve (small $\mathrm{M}$ wave, large $\mathrm{H}$ wave) were deemed optimal for paired pulse analysis. At the end of the experiment, to further verify the $\mathrm{H}$ reflex, an axotomy was 

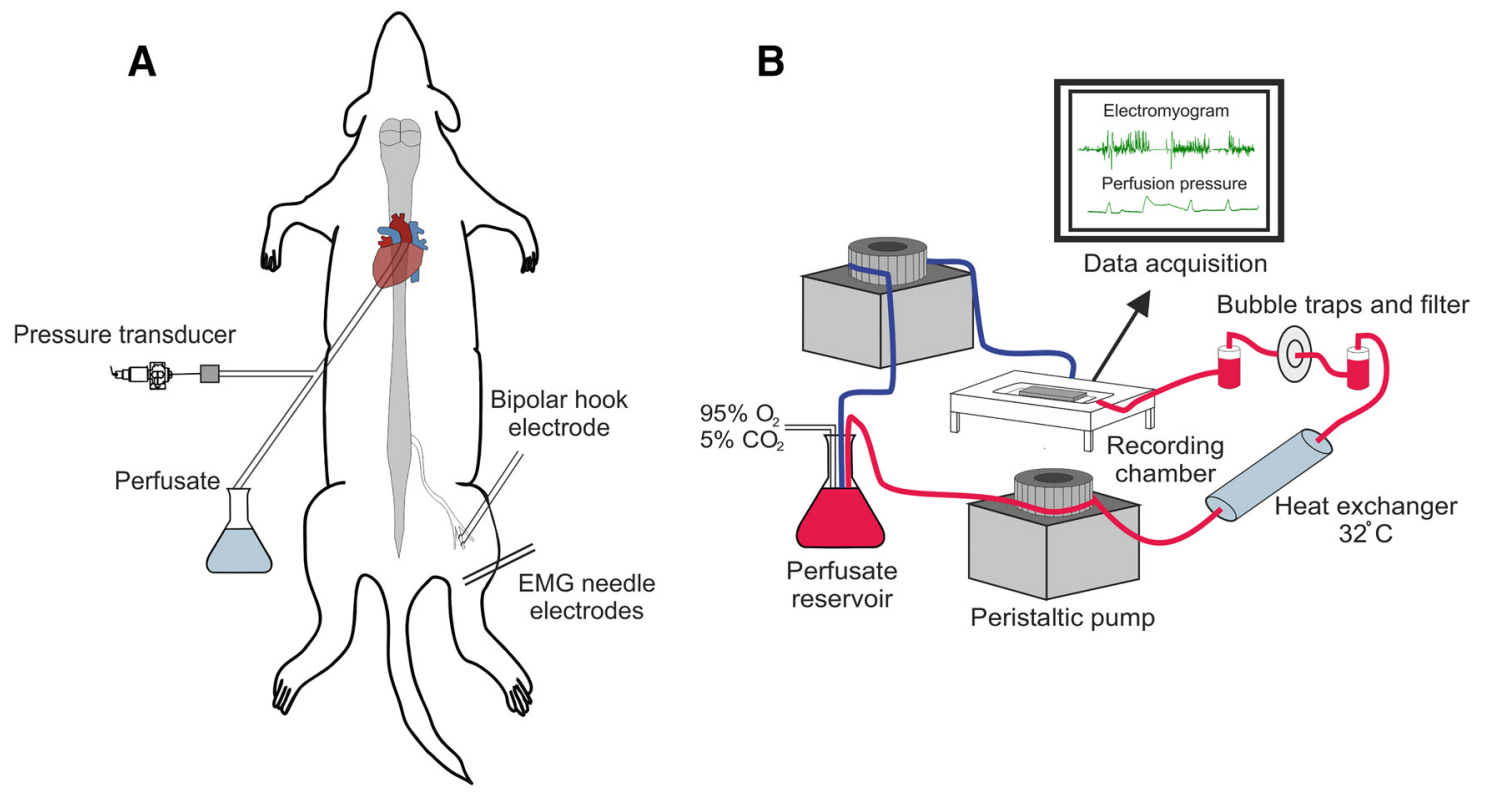

Figure 1. Preparation setup. $\boldsymbol{A}$, Schematic of animal setup with cannulation, recording, and stimulation sites shown. Animal is in the prone position. $\boldsymbol{B}$, Components of the perfusion circuit and flow of ACSF. Red line represents flow from reservoir to preparation and the blue line represents the return flow. Two pumps are shown for clarity; all tubing actually inserts into a single pump.
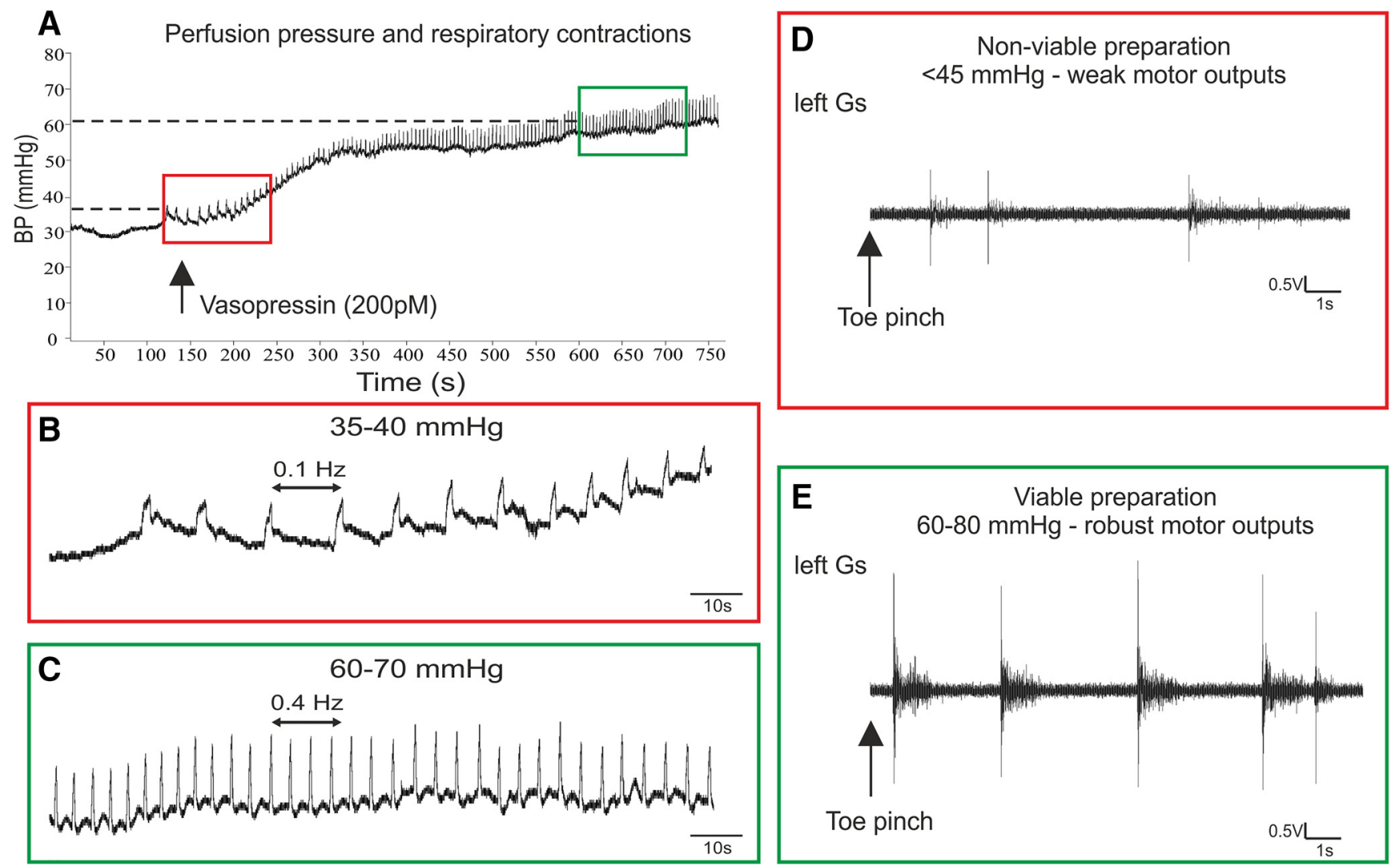

Figure 2. Establishing preparation viability. $A$, Vasopressin increases systemic pressure, leading to higher frequency of respiratory contractions. Red box shows respiratory contractions at low, nonviable pressure; green box indicates high, viable pressure. $\boldsymbol{B}$, Weak, low-frequency respiratory contractions at low pressure. $\boldsymbol{C}$, Respiratory frequency markedly increases with increased pressure indicating brainstem viability. $\boldsymbol{D}-\boldsymbol{E}$, Motor (EMG) outputs from the left gastrocnemius in response to toe pinch at viable and nonviable systemic pressures.

performed by severing the nerve between the hook electrode and the exit of the mixed sciatic nerve from the spinal cord (Fig. 3D). This severed the sensory and motor nerves to and from the spinal cord but retained the motor axons between the hook and recording electrodes. Axotomy dem- onstrated that the $\mathrm{H}$ reflex was abolished but a strong $\mathrm{M}$ wave was retained (Fig. 3E).

Paired-pulse stimulation was used to assess excitability of the central circuits by evaluating the $\mathrm{H}$ reflex and its modulation. Dual pulses were 


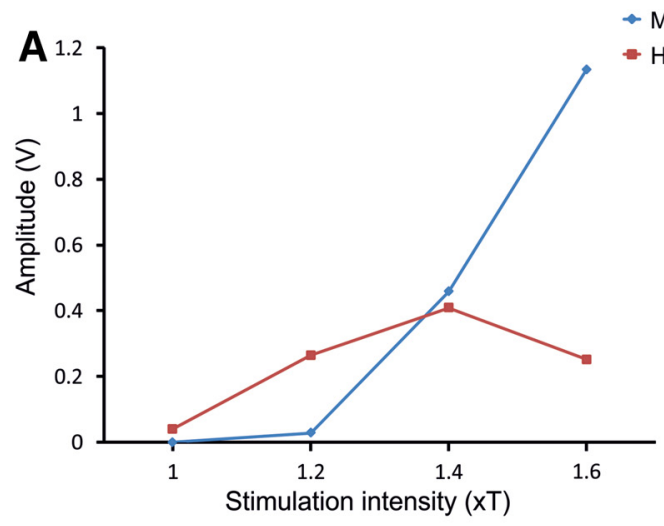

D

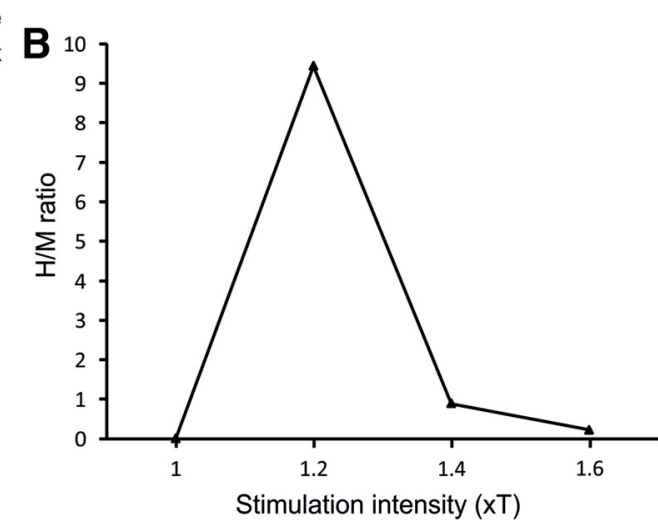

$\mathbf{E}$

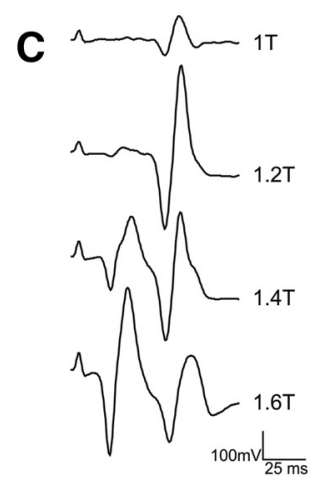

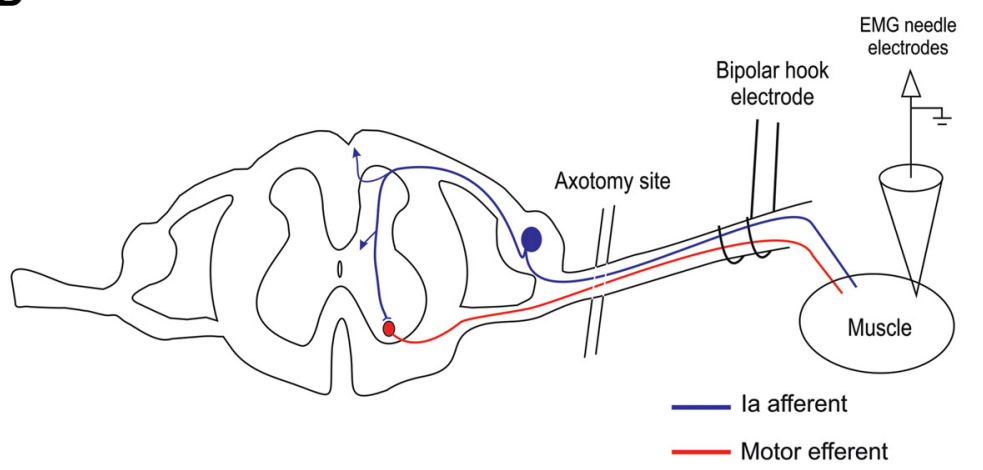

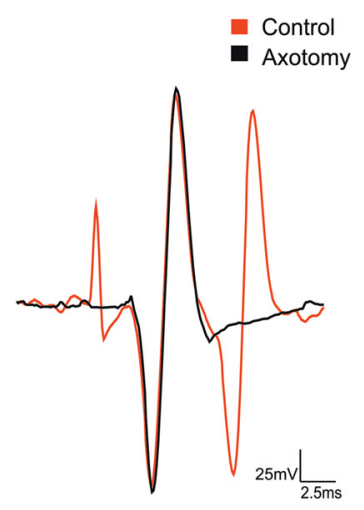

Figure 3. Stimulation and recording setup. $A, B$, Typical $H$ reflex recruitment curves demonstrating classical $H$ and $M$ wave responses to increased stimulation strength. $C$, Typical $H$ reflex responses to graded stimulation. $\boldsymbol{D}$, Experimental setup showing stimulation, recording, and axotomy sites. $\boldsymbol{E}$, H reflex was confirmed by severing the sciatic nerve at the site marked in $\boldsymbol{D}$, resulting in loss of $\mathrm{H}$ wave but unaffected $\mathrm{M}$ wave.

administered to the nerve at intervals ranging from 1 to $700 \mathrm{~ms}$ and the level of depression was calculated to produce a depression curve. At least 15 traces were recorded for each interval tested and there was a minimum rest period of $1 \mathrm{~min}$ between trials. Control (single pulse) trials, also consisting of 15 traces, preceded each test trial for direct comparison and normalization.

\section{Data analysis}

EMG signals were recorded using a unit gain amplifier head stage (NL100; Digitimer) connected to a Neurolog amplifier $(1000 \times$ amplification; NL 900D; Digitimer). Signals were band-pass filtered between 50 and 10,000 $\mathrm{Hz}$ and digitized using an analog-to-digital interface (1401micro; Cambridge Electronic Design) and the data stored on a PC. The data were visualized using Spike2 software (Cambridge Electronic Design) running on the PC, where the data were saved for offline analysis. Raw traces were analyzed using Signal 2.7 (Cambridge Electronic Design). Signal 2.7 was also used to generate the $\mathrm{H}$ reflex trace averages $(n=15)$ at each threshold/interval. Latencies were measured as peak to peak and amplitudes as the absolute maximum of the averaged traces. $\mathrm{H}$ waves were always normalized to either $M_{\max }$ or the amplitude of the averaged control $\mathrm{H}$ wave (15 averaged waves).

\section{Surgical procedures}

Spinal cord transection. To assess the development of spinal circuits in the absence of descending input, neonatal (P5) spinal cord transections were performed. To determine litter age with an accuracy of $\pm 3 \mathrm{~h}$, pregnant mothers were checked 3 times per day from gestational day 19 (E19) until the litter was born. Litters born overnight were not used because there could be error of up to $12 \mathrm{~h}$. The day of birth was called P0 and all transections took place at $\mathrm{P} 5$.

All pups were separated from the mother immediately before surgery. Pups were washed thoroughly with saline and then deeply anesthetized (loss of paw withdrawal) using isoflurane (4\% induction, maintained at
$1.5 \%)$. Upon loss of withdrawal reflex, pups were subcutaneously injected with warm saline $\left(37^{\circ} \mathrm{C}, 200 \mu \mathrm{l}\right)$ and a midline, dorsal incision was made to the skin near the base of the scapulae. The paravertebral muscles were retracted laterally to reveal the midthoracic vertebral laminae. A midthoracic (T8-10) laminectomy was performed and the cord and meninges were completely severed using microscissors. Completion of the transection was ensured by observing the base of the vertebral canal and complete separation of the two distal stumps of the spinal cord. Postmortem histological examination of the injury confirmed surgical observation of completion. A piece of Gelfoam was then inserted into the cavity and the wound was closed with silk sutures. Buprenorphine was administered at $0.1 \mathrm{mg} / \mathrm{kg}$ before the pups regained consciousness to relieve pain. Pups were placed in an incubator to recover fully before being returned to the mother.

Cholera toxin $\beta$ injections. During the same surgery, cholera toxin $\beta$ $(7.5 \mathrm{mg} / \mathrm{ml})$ was pressure injected into the gastrocnemius muscle using a glass micropipette attached to a Hamilton syringe. A small incision was made over the medial gastrocnemius muscle, the needle was inserted, and $1 \mu \mathrm{l}$ was slowly injected. The needle was left in the muscle for $5 \mathrm{~min}$ and retracted very slowly to prevent leakage.

\section{Immunohistochemistry}

Tissue processing. After $\mathrm{H}$ reflex recordings, preparations were moved to a fume hood perfusion circuit and transcardially perfused with $4 \%$ paraformaldehyde in $0.1 \mathrm{~m}$ phosphate buffer. Vertebral columns containing the spinal cords of animals were harvested and postfixed overnight (4\% PFA). Spinal cords were dissected out of the bony casing and cryoprotected in sucrose (30\% in PBS) for at least $48 \mathrm{~h}$. Segments T13-S1 of the spinal cord were separated and frozen in optimal cutting temperature compound (OCT; Leica Biosystems). A cryostat (1850; Leica Biosystems) was then used to cut transverse serial sections $(25 \mu \mathrm{m})$ of $\mathrm{L} 4-5$, which were used for all analyses in this study. 


\begin{tabular}{lll}
\hline Antibodies & Source & ID \\
\hline Motoneurons: goat anticholine acetyltransferase (ChAT) polyclonal antibody & Millipore & Catalog \#AB144P, RRID:AB_90661 \\
PA terminals: guinea pig anti-vesicular glutamate transporter 1 (VGLUT1) polyclonal antibody & Millipore & Catalog \#AB5905, RRID:AB_2301751AB_2301751 \\
Renshaw cells: calbindin D28k antibody & Swant & Catalog \#C9638, RRID:AB_2314070 \\
GABApre terminals: mouse antiglutamate decarboxylase, 65 kDa isoform, clone GAD-6 antibody & Millipore & Catalog \#MAB351, RRID:AB_2263126 \\
Cholinergic terminals: goat antivesicular acetylcholine transporter polyclonal antibody & Millipore & Catalog \#AG260, RRID:AB_100003 \\
\hline
\end{tabular}

All immunohistochemical staining was conducted using the same principle steps. Free floating sections were washed in PBS $(3 \times 10 \mathrm{~min})$ and then blocked in 3\% normal donkey serum and phosphate buffer $(0.01 \mathrm{M})$ with $0.2 \%$ Triton X-100 (PBST) for $1 \mathrm{~h}$ before being incubated overnight in primary antibodies (Table 1) for $24-48 \mathrm{~h}$. Sections were then incubated in secondary antibodies that had been raised primarily in donkey and against the $\operatorname{Ig}(\operatorname{IgG})$ in which the primary antibody had been raised. The secondary antibodies were conjugated to Alexa Fluor 488 or 555 and biotinylated antibodies were revealed using avidin-Pacific Blue (Invitrogen). All antibodies were diluted in blocking solution (same concentrations as blocking step).

\section{Imaging and analysis of IHC data}

Confocal imaging and quantification of boutons. All images were taken using a confocal LSM 700 at $63 \times$ (oil immersion). The same microscope was used for the entirety of any experiment. For most analyses, the pinhole was adjusted to $1 \mu \mathrm{m}$ optical slices and images were taken as close to the center of the cell as possible (nucleus visible). All motoneurons on triplicate sections from L $4-5$ were imaged per animal. All " $n$ " values refer to animal numbers. Synaptic boutons were only included if they were in close apposition to the neuron and the count was normalized to $100 \mu \mathrm{m}$ of the neuron perimeter. Tile scans of whole sections were taken at $20 \times$ magnification through one confocal plane and all sections were imaged using the same settings. For quantification of lamina distribution of vesicular glutamate transporter 1 (VGLUT1), two regions of interest (ROIs) were defined: dorsal $\left(\mathrm{ROI}^{\mathrm{d}}\right)$ and intermediate $\left(\mathrm{ROI}^{\mathrm{i}}\right)$. To account for changes in size of the spinal cord sections with age, the ROIs were normalized to the size of the section based on anatomical landmarks. The dorsal ROI box dimensions were normalized by: height $=25 \%$ of the length of a straight line from base of dorsal column to cord dorsum; width $=20 \%$ of horizontal line from base of dorsal column laterally to termination of gray matter. The intermediate ROI was the height of the central canal and extended from the lateral edge of the central canal to the lateral termination of the gray matter. ImageJ particle analysis was used to quantify the density of VGLUT $1^{+}$terminations in the defined regions. First, images were converted to binary and a minimum bouton diameter of $2 \mu \mathrm{m}$ was defined as the threshold (Ichiyama et al., 2006). All measurements of density were expressed as percentage coverage of the total area of the ROI analyzed. Motoneurons selected for analysis of synaptic coverage were chosen based on size. All motoneurons were imaged, but only cells with a diameter $>25 \mu \mathrm{m}$ were analyzed because $\gamma \mathrm{MNs}$ tend to be $<20 \mu \mathrm{m}$ in diameter (Ichiyama et al., 2006).

$Z$-stacks and $3 D$ reconstruction. In some cases, it was necessary to use $Z$-stack images to analyze cells that received very few contacts or if the contacts were mainly distributed on dendrites (Mentis et al., 2006). This protocol was also used for quantification of axo-axonic presynaptic contacts because it is impossible to identify reliably the center of the VGLUT $1{ }^{+}$terminal in the $z$ plane. In these cases, $0.5 \mu \mathrm{m}$ steps were used with a $63 \times$ lens through the entirety of the cell and its dendrites. Images were reconstructed using Imaris 8.1 (Bitplane) and 3D rendered cells were used to quantify surface area and verify terminal contact.

Analyses of $\mathrm{VGLUT1}^{+}$contacts on RCs. For at least three animals per group, RCs from three free-floating sections were analyzed. Total cell numbers per group were as follows: Intact: P10 $=72, \mathrm{P} 14=59$, and $\mathrm{P} 21=56$; TX at P5 (P5TX): $\mathrm{P} 10=74, \mathrm{P} 14=55$, and P21 $=62$. The length of the dendrites analyzed was the first $50 \mu \mathrm{m}$ for every cell. 3D reconstructions were quantified by normalizing VGLUT1 ${ }^{+}$contacts to RC surface area (number of VGLUT1 boutons $/ 100 \mu \mathrm{m}^{2}$ ).
Analyses of GABApre ' $P$ ' bouton contacts on $V G L U T 1^{+} P A s .3 \mathrm{D}$ reconstructions were quantified by normalizing number of $\mathrm{P}$ boutons to $\mathrm{VGLUT1}^{+} \mathrm{PA}$ surface area (number of P boutons $/ 10 \mu \mathrm{m}^{2}$ ). P bouton contacts were only quantified on VGLUT1 ${ }^{+}$PAs that were closely apposed to $\mathrm{ChAT}^{+} \mathrm{MNs}$. There were at least three animals per group, with three free floating sections analyzed per animal. The total number of VGLUT1 ${ }^{+}$PAs on which P boutons were quantified were as follows: intact: $\mathrm{P} 10=572, \mathrm{P} 14=500$, and $\mathrm{P} 21=474$; P5TX: P10 $=400, \mathrm{P} 14=$ 483 , and P21 $=463$.

\section{Statistics}

All statistical tests were performed using the IBM SPSS 22 statistics package. Tests for normal distribution of data were performed before comparisons were made. In cases in which the data were distributed normally, univariate ANOVA tests were performed with Bonferroni post hoc for pairwise comparisons. For data that were not distributed normally, Kruskal-Wallis tests were used with Bonferroni corrections performed on multiple comparisons produced by Dunn's tests. For comparing $H_{\max } / M_{\max }$ or threshold values between intact and P5TX at P14 only, Mann-Whitney $U$ tests were performed.

\section{Results}

To create a longitudinal profile of sensorimotor circuit development, we targeted ages P10, P14, and P21. At P10, motor control in rats is immature. P14 marks a dramatic transition to near mature motor control and, at P21, the motor system is considered largely indistinguishable from adult rats.

\section{Normal development of proprioceptive afferents in the presence and absence of descending systems}

In the cervical spinal cord, PAs and descending systems develop in an activity-dependent, competitive manner. The cervical cord is functionally distinct from the lumbar cord of the rat in that the forelimbs are used for skilled tasks (grasping and manipulation) and locomotion. Reaching and grasping involve fine control of small muscles in the forepaws, whereas the lumbar spinal circuitry is less associated with such fine control. This led us to investigate whether PAs in the lumbar cord develop differently from the cervical cord and if their developmental profile was dependent on the presence of descending systems.

\section{Normal postnatal development of PA innervation of the lumbar spinal cord}

Using an antibody against VGLUT1 to identify PAs, density of terminals was assessed in dorsal and intermediate regions of interest in the spinal cord, as well as directly onto MNs. Results showed reduced VGLUT1 ${ }^{+}$terminal density in dorsal, intermediate, and ventral regions (MNs) of the spinal cord between P10 and P14; however, in most cases, there was little change between P14 and P21. In the dorsal horn, there was a significant effect of development on PA termination densities ( $p=0.008$; Fig. $4 H)$. Densities were significantly greater in P10 animals (63.64 \pm $1.46 \%, n=3$ ) compared with P14 (39.11 $\pm 3.76 \%, p=0.012$, $n=4)$ and P21 (42.31 \pm 5.27\%, $p=0.023, n=5$; Fig. $4 H)$ animals, but there was no difference between P14 and P21 ( $p=$ 

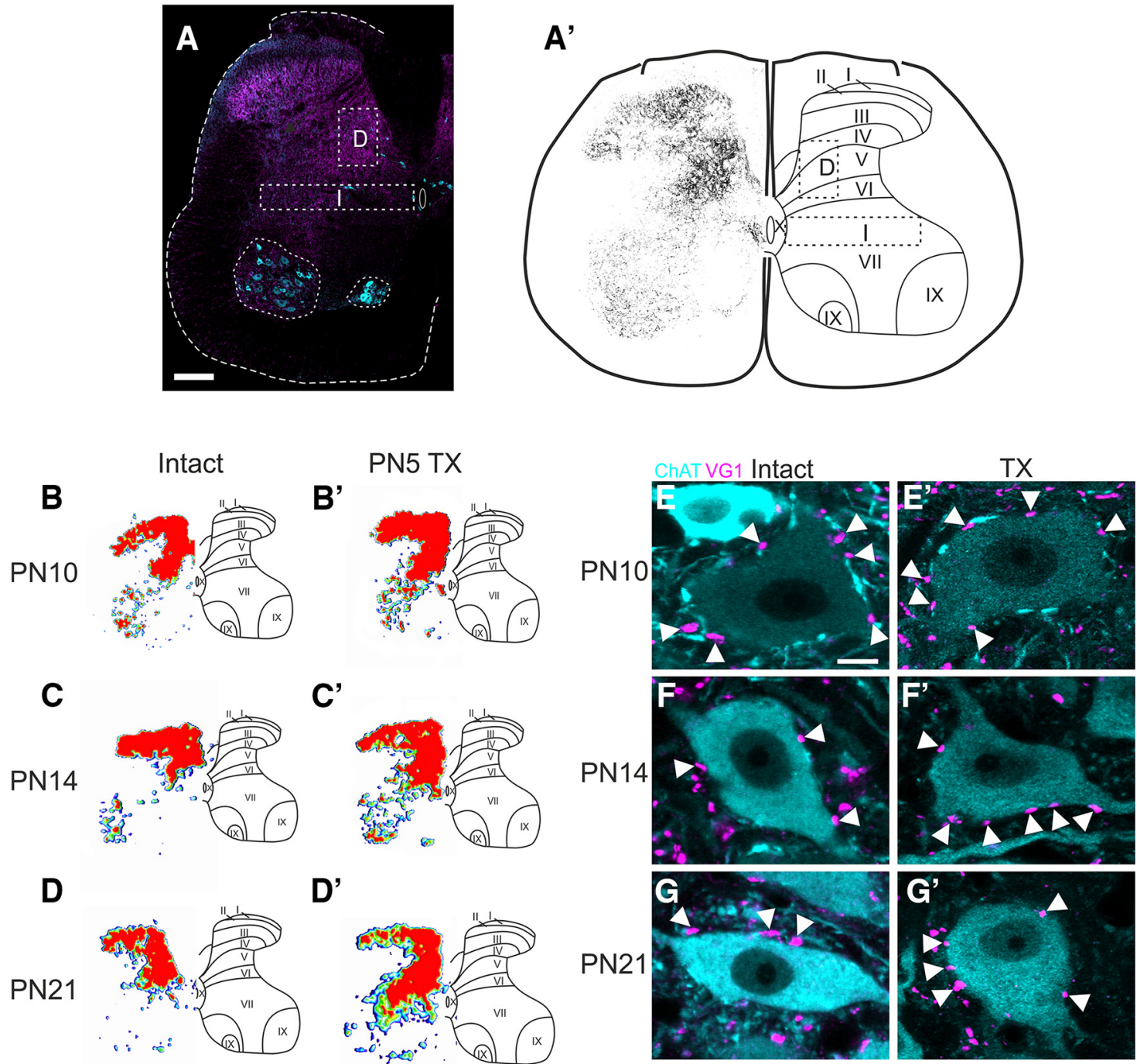

D'
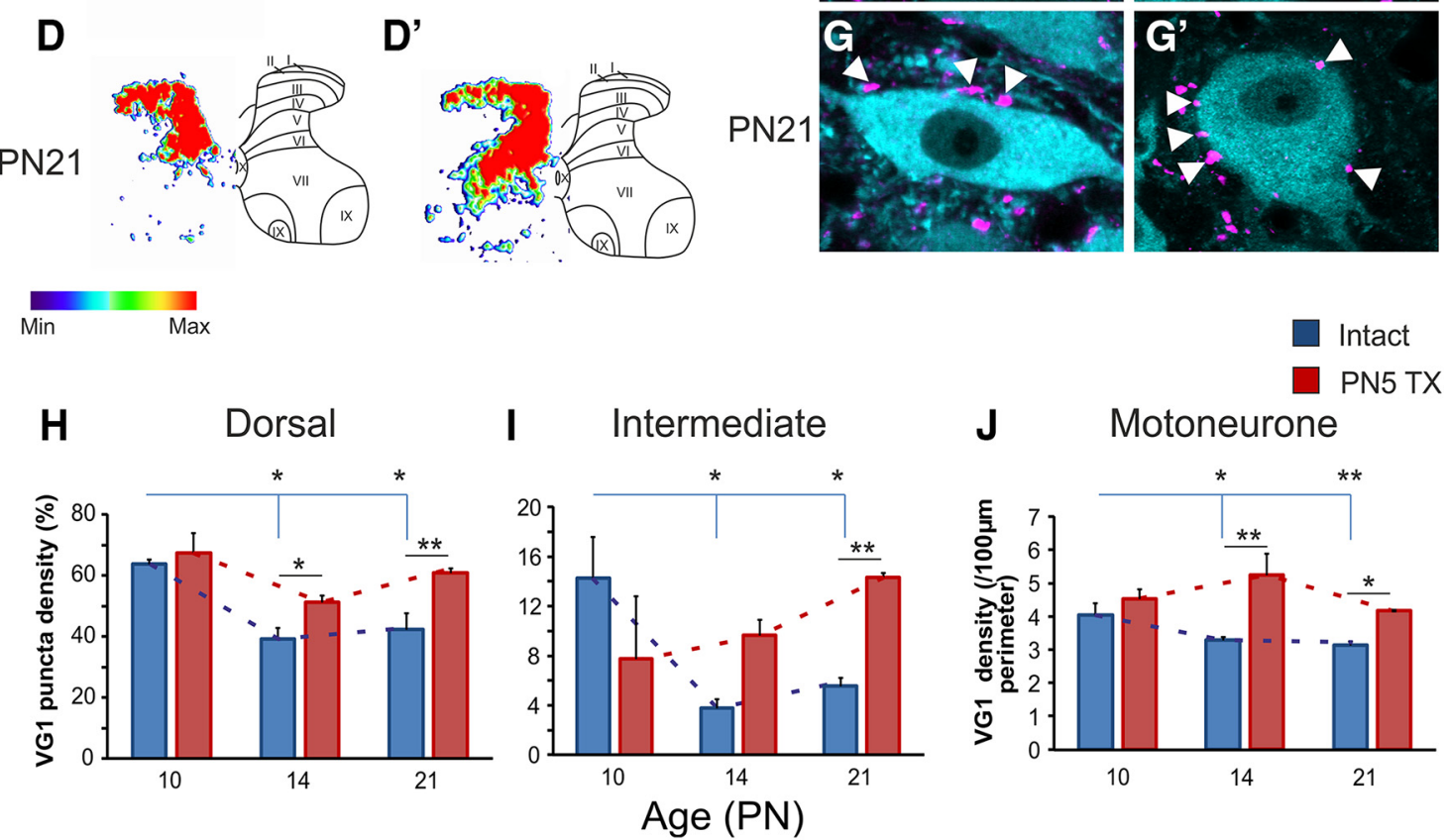

Figure 4. Postnatal development ofVGLUT1 ${ }^{+}$terminations in the lumbar spinal cord. $\boldsymbol{A}$, Typical VGLUT1 ${ }^{+}$staining with dorsal, intermediate, and ventral regions of interest marked. $\boldsymbol{A}^{\prime}$, Images were converted to binary for assessment of bouton density in dorsal and intermediate regions of interest. $\boldsymbol{B}-\boldsymbol{D}^{\prime}$, Representative heat maps of VGLUT1 ${ }^{+}$puncta densities at P10 -P21 in intact and P5TX rats. Thresholding is based on maximum and minimum densities. $\boldsymbol{E}-\boldsymbol{G}^{\prime}$, Representative images of MNs contacted by PA boutons throughout development in intact and P5TX rats. $\boldsymbol{H}-\boldsymbol{J}$, Quantification of boutons in dorsal $(\boldsymbol{H})$ and intermediate $(\boldsymbol{I})$ regions of interest and on $\operatorname{MNs}(\boldsymbol{J})$. Scale bars: $\boldsymbol{A}, 200 \mu \mathrm{m} ; \boldsymbol{E}, 10 \mu \mathrm{m}$.

0.830 ), suggesting that the development of these inputs ceases at this stage. In the intermediate region, there was also a significant effect of age on VGLUT ${ }^{+}{ }^{+}$terminal density $(p=0.020$; Fig. $4 I)$. Similar to the dorsal horn, there was a reduction in VGLUT1 ${ }^{+}$ terminal density between P10 (14.31 $\pm 3.32 \%)$ and P14 (3.78 \pm
$0.70 \%, p=0.029)$ and P21 $(5.59 \pm 0.65, p=0.049)$, but there was no difference between P14 and P21 ( $p=0.803)$. In the dorsal and intermediate gray, $\mathrm{VGLUT} 1{ }^{+}$boutons are also sourced from the CST and low threshold mechanosensory fibers, which both undergo significant postnatal changes (Varoqui et al., 2002; Todd et 
al., 2003; Fitzgerald, 2005; Martin, 2005; Du Beau et al., 2012). However, in contrast to both proprioceptive and cutaneous afferents, CST axons proliferate in the lumbar gray between P10 and $\mathrm{P} 14$, indicating that reduced VGLUT1 ${ }^{+}$bouton density in dorsal and intermediate regions is solely due to afferent retraction and most likely underestimated (Donatelle, 1977; Joosten et al., 1989).

In the ventral horn, there was a significant effect of age ( $p=$ $0.005)$ on VGLUT $1^{+}$terminal density in close apposition with MNs (Fig. $4 J$ ). At P10 (4.51 \pm 0.24 boutons $/ 100 \mu \mathrm{m}$ soma perimeter, $n=3$; Fig. $4 E)$, the density of VGLUT1 ${ }^{+}$boutons on MNs were greater than at P14 (3.46 $\pm 0.26, p=0.031, n=3$; Fig. $4 F)$ and P21 (3.1 $\pm 0.26, p=0.006, n=3$; Fig. $4 G)$; however, there was no difference between P14 and P21 $(p=0.632)$.

\section{Neonatal transection prevents retraction of proprioceptive afferents in the lumbar spinal cord}

After P5TX, retraction of VGLUT1 ${ }^{+}$terminals observed during normal development was completely abolished. In dorsal and intermediate regions, CST axons and cutaneous afferents are also VGLUT1 ${ }^{+}$(Alvarez et al., 2004; Du Beau et al., 2012). Considering that CST is absent after TX and the only other sources of this VGLUT1 are proprioceptive and cutaneous afferents, we can conclude that developmental retraction of afferents is abolished in the absence of descending systems. In the dorsal region, there was no difference between intact and TX groups at P10 (intact: $63.64 \pm 1.46$; TX: $67.33 \pm 6.63, p=0.512, n=3$; Fig. $\left.4 B, B^{\prime}\right)$; however, at both P14 (intact: $39.10 \pm 3.75$; TX: $51.23 \pm 2.10, p=$ 0.030, $n=3$; Fig. $4 C, C^{\prime}$ ) and P21 (intact: $42.32 \pm 5.27$; TX: $60.88 \pm 1.46, p=0.030, n=3$; Fig. $\left.4 D, D^{\prime}\right)$, the TX groups had greater densities of VGLUT1 ${ }^{+}$puncta (Fig. $4 H$ ). For intermediate regions (Fig. 4I), again, the normal developmental trend was abolished for VGLUT ${ }^{+}$boutons $(p=0.356)$. There was no difference between groups at P10 (intact: $14.31 \pm 3.32$; TX: $7.88 \pm 5.02, p=0.645)$. At P14, there was also no difference between the intact and the TX groups (intact: $3.78 \pm 0.70$; TX: $9.67 \pm 1.26, p=0.060)$. At P21, neonatal TX resulted in a greater density of VGLUT1 puncta (intact: $5.59 \pm 0.65$; TX: $14.33 \pm 0.34$, $p=0.010)$.

On MNs, significant retraction of PA boutons during normal development was abolished by P5TX ( $p=0.514$; Fig. $\left.4 E-G^{\prime}, J\right)$. At P10, VGLUT1 ${ }^{+}$puncta densities were not different between groups (intact: $4.508 \pm 0.25$; TX: $4.53 \pm 0.44, p=0.966, n=3$; Fig. $\left.4 E, E^{\prime}\right)$; however, TX groups had greater densities at both $\mathrm{P} 14$ (intact: $3.46 \pm 0.28$; TX: $4.99 \pm 0.44, p=0.009, n=3$; Fig. $4 F, F^{\prime}$ ) and P21 (intact: $3.14 \pm 0.28$; TX: $4.18 \pm 0.36, p=0.034, n=3$; Fig. $\left.4 G, G^{\prime}\right)$.

\section{Descending systems are necessary for retraction of PAs from Renshaw cells}

A lack of normal retraction of afferents from dorsal and intermediate zones and MNs suggests that interneuron populations may also be affected by P5TX. To test this, we assessed VGLUT1 ${ }^{+}$ terminal density on Renshaw cells, which reportedly originate exclusively from PA afferents (Mentis et al., 2006).

\section{PA terminals are retracted from RCs during postnatal development}

Antibodies against calbindin D-28k revealed Renshaw cells and extensive portions of their proximal dendrites in the ventral horn of the lumbar spinal cord (Fig. $5 A-A^{\prime \prime}$ ). Because PA terminals on RCs are sparse and mainly distributed on their dendritic processes, 3D reconstructions of calbindin ${ }^{+}$RCs and PA boutons were used to quantify terminals contacting the soma and dendrites (Fig. $5 A-B^{\prime \prime}$ ). During normal development, there was a significant retraction of PA terminals from RCs $(p=0.014)$. This was true for the soma $(p=0.004$; Fig. $5 F)$, dendrites $(p=0.003)$, and cells overall $(p=0.05)$. For the whole cell (soma and dendrites combined), there was a reduction in PA terminations on RCs between P10 $\left(1.21 \pm 0.06 / 100 \mu \mathrm{m}^{2}, n=3\right)$ and P14 (0.68 \pm $0.15, n=3, p=0.011)$ and between P10 and P21 (0.63 \pm 0.11 , $n=3, p=0.008)$; however, this reduction in PA input plateaus at P14 because there was no significant difference between P14 and P21 $(p=0.76)$. On the soma, there was a significant difference between P10 (0.72 \pm 0.02$)$ and P14 (0.52 $\pm 0.09, p=0.043)$ and $\mathrm{P} 21(0.27 \pm 0.02, p=0.001)$. In addition, there was a decrease between P14 and P21 ( $p=0.022)$. For the dendrites, we saw a significant reduction in PA contacts between P10 (1.92 \pm 0.08$)$ and P14 (1.17 $\pm 0.14, p=0.002)$ and P21 $(1.15 \pm 0.06, p=$ $0.002)$; however, there was no difference between P14 and P21 $(p=0.94)$.

\section{Neonatal transection disrupts development of PA boutons on RCs}

In the P5TX group, there was no effect of age on postnatal development of PA terminals contacting RCs $(p=0.144)$, suggesting that development was significantly disrupted. The effect of age was abolished on the soma and there were no significant differences between the intact and TX groups at any of the ages compared (P10 intact: $0.716 \pm 0.02 / 100 \mu \mathrm{m}^{2}$; TX: $0.66 \pm 0.12, n=3$, $p=0.62$, P14 intact: $0.52 \pm 0.09$; TX: $0.76 \pm 0.06, n=3, p=$ 0.057; and P21 intact: $0.27 \pm 0.02$; TX: $0.43 \pm 0.11, p=0.213$, $n=3$; Fig. $5 F$ ). On the proximal dendrites of RCs, again P5TX acted to disrupt retraction of PAs. When each time point was considered, intact and TX groups were not statistically different at P10 (intact: $1.92 \pm 0.08 / 100 \mu \mathrm{m}^{2}$; TX: $1.85 \pm 0.27, p=0.768$; Fig. $5 G$ ) and P21 (intact: $1.15 \pm 0.07$; TX: $1.23 \pm 0.27, p=0.774$ ) but the TX group had greater PA puncta density at P14 (intact: $1.17 \pm 0.14$; TX: $1.80 \pm 0.08, p=0.027$; Fig. $\left.5 D, D^{\prime}, G\right)$. When values for dendrites and soma were combined to evaluate the whole cell, again, development was shown to be disrupted ( $p=$ 0.063 ). There was no significant difference between the intact and the TX groups at P10 (intact: $1.21 \pm 0.07 / 100 \mu \mathrm{m}^{2}$; TX: $1.07 \pm$ $0.10, p=0.454$ ) or P21 (intact: $0.63 \pm 0.10$; TX: $0.92 \pm 0.05, p=$ $0.454)$, but at $\mathrm{P} 14$, the transection group had a greater density of PA boutons apposing Renshaw cells (intact: $0.67 \pm 0.15$; TX: $1.36 \pm 0.16, p=0.002$ ). Therefore, we show that P5TX disrupts development of PA inputs to RCs due to significantly greater density at P14.

\section{Neonatal transection disrupts the normal development of motor axon collaterals on Renshaw cells}

Motor axon collaterals provide excitatory drive to adult RCs in a recurrent inhibition circuit exhibiting remarkable efficacy (Moore et al., 2015). Because of the lack of PA retraction after P5TX shown above, we wanted to assess whether this had any bearing on the development of motor axon inputs to RCs. This was done by quantifying $\mathrm{VAChT}^{+}$boutons on RCs (Fig. 6A-E) throughout development in the presence and absence of descending systems.

Intact animals did not exhibit a significant effect of age on RC $\mathrm{VAChT}^{+}$terminals, suggesting that these remained relatively stable throughout development (Fig. 6E). In the P5TX group, there was a significant effect of age $(p=0.005)$, suggesting that P5TX significantly altered the developmental profile. Comparisons of val- 


\section{IMARIS 3D reconstruction of Renshaw cells}
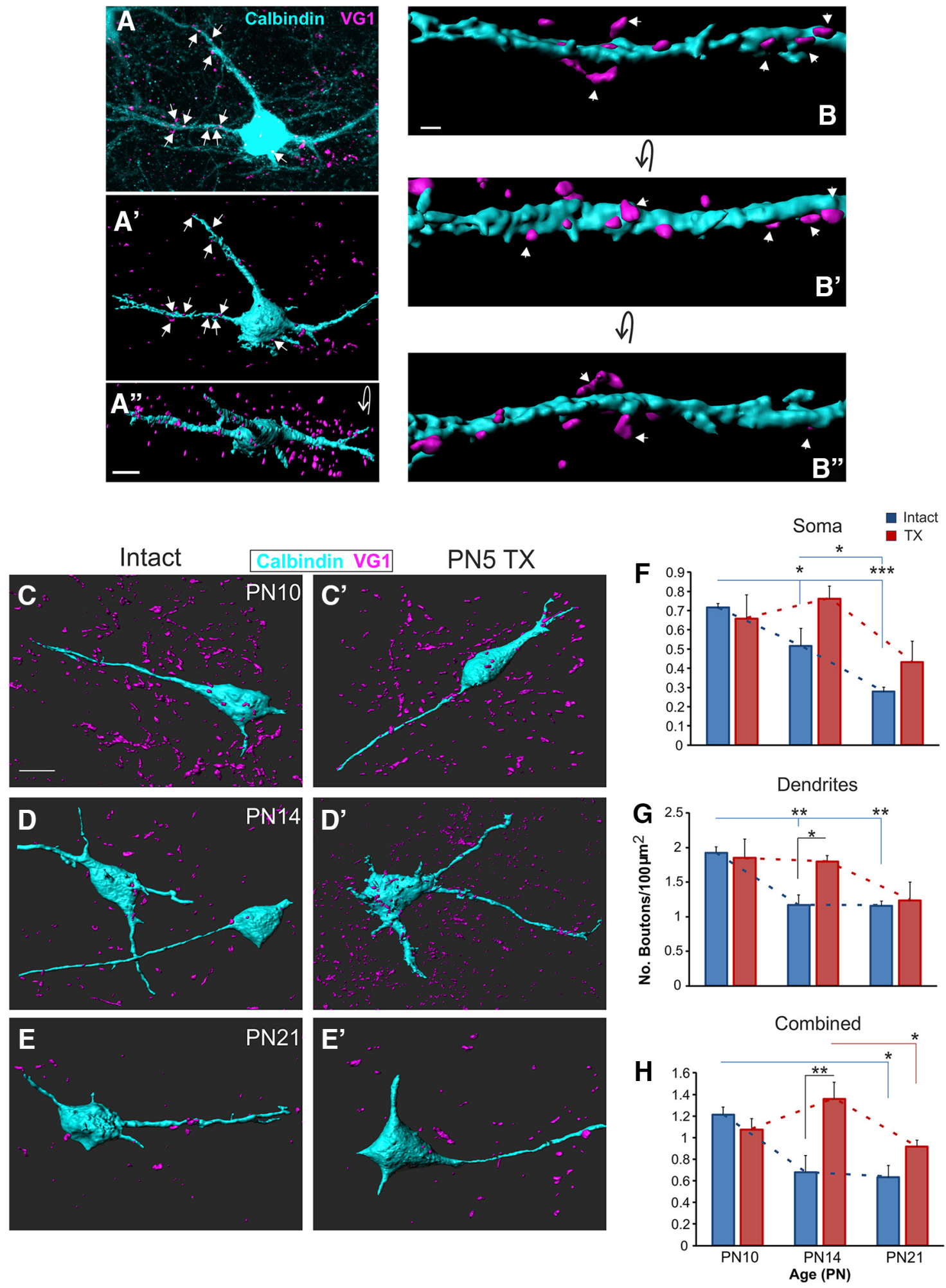

Figure 5. Postnatal development of PA boutons on Renshaw cells. $\boldsymbol{A}-\boldsymbol{B}^{\prime \prime}, 3 \mathrm{D}$ reconstruction of Renshaw cell and PA contacts created using IMARIS software. $\boldsymbol{C}-\boldsymbol{E}^{\prime}$, Representative RCs and PA contacts at P10 -P21 in intact and P5 TX rats. $\boldsymbol{F}-\boldsymbol{H}$, Quantification of boutons contacting the soma, dendrites, and the whole cell for both intact and P5 TX rats at each age. Scale bars: $\boldsymbol{A}^{\prime \prime}$, $\boldsymbol{C}, 10 \mu \mathrm{m}$; $B, 2 \mu \mathrm{m}$.

ues for the two groups at each age revealed no significant differences at P10 (intact: $3.86 \pm 0.64 / 100 \mu \mathrm{m}$ soma perimeter, $n=3 \mathrm{TX}=3.94 \pm 0.33, n=3$ ) or P14 (intact: $4.50 \pm 0.82, n=$ $3, \mathrm{TX}=4.45 \pm 0.12, n=3, p=0.954)$; however, there were significantly fewer $\mathrm{VAChT}^{+}$boutons on RCs from P5TX spinal cords at P21 (intact: $4.77 \pm 0.38, n=3$; TX: $2.78 \pm 0.18, n=3$, $p=0.013)$.

In summary, it is likely that the lack of PA retraction after P5TX results in a subsequent decrease in motor axon synapses (Fig. 6F, $F^{\prime}$ ). 

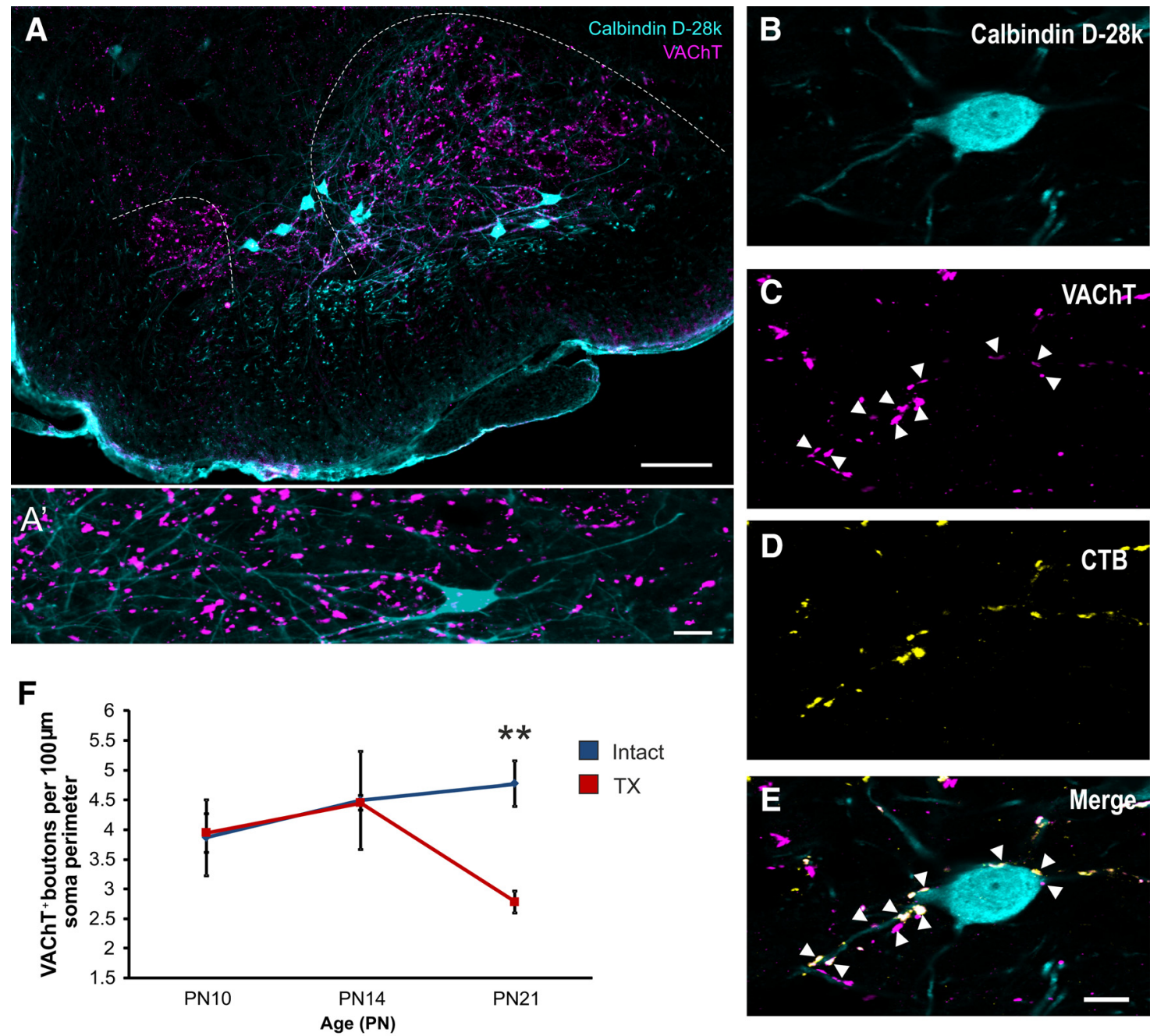

G

Intact PN14-21

G'

PN5 TX PN14-21
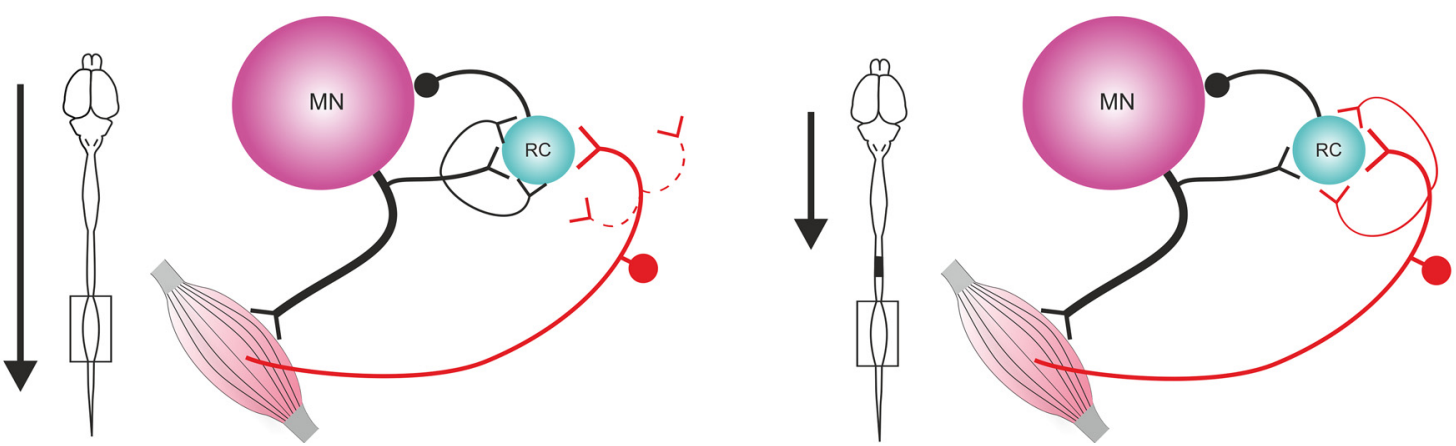

Figure 6. Postnatal development of motor axon collaterals on Renshaw cells. $\boldsymbol{A}, \boldsymbol{A}^{\prime}$. Renshaw cells and VAChT ${ }^{+}$boutons in the ventral horn. $\boldsymbol{B}-\boldsymbol{E}$, calbindin ${ }^{+}$Renshaw cells contacted by $\mathrm{VAChT}^{+}$motor axon collaterals. $\boldsymbol{F}$, Graph showing reduction in motor axon collateral density on RCs between P14 and P21. G, $\mathbf{G}^{\prime}$, Schematics illustrating differences between intact and P5TX rats in development of PAs and motor axon inputs to RCs. Scale bars: $A, 100 \mu \mathrm{m} ; \boldsymbol{A}^{\prime}, \boldsymbol{E}, 10 \mu \mathrm{m}$.

\section{Postnatal development of GABApre projections to PA} terminals in the presence and absence of descending systems Proprioceptive afferent activity is heavily modulated by axoaxonic contacts (P boutons) from GABApre neurons via presynaptic inhibition (Hughes et al., 2005; Rudomin, 2009). It has been suggested recently that differentiation of GABApre projections depends upon the availability of target PA termi- nals and local glutamate signaling (Betley et al., 2009; Mende et al., 2016). The extreme developmental retraction of PAs and lack thereof after P5TX provided a unique assay with which to characterize the developmental profile of GABApre projections and their dependence on both sensory and descending inputs. GAD $65^{+}$boutons contacting PA terminals, which apposed MNs directly, were quantified using 3D IMARIS recon- 

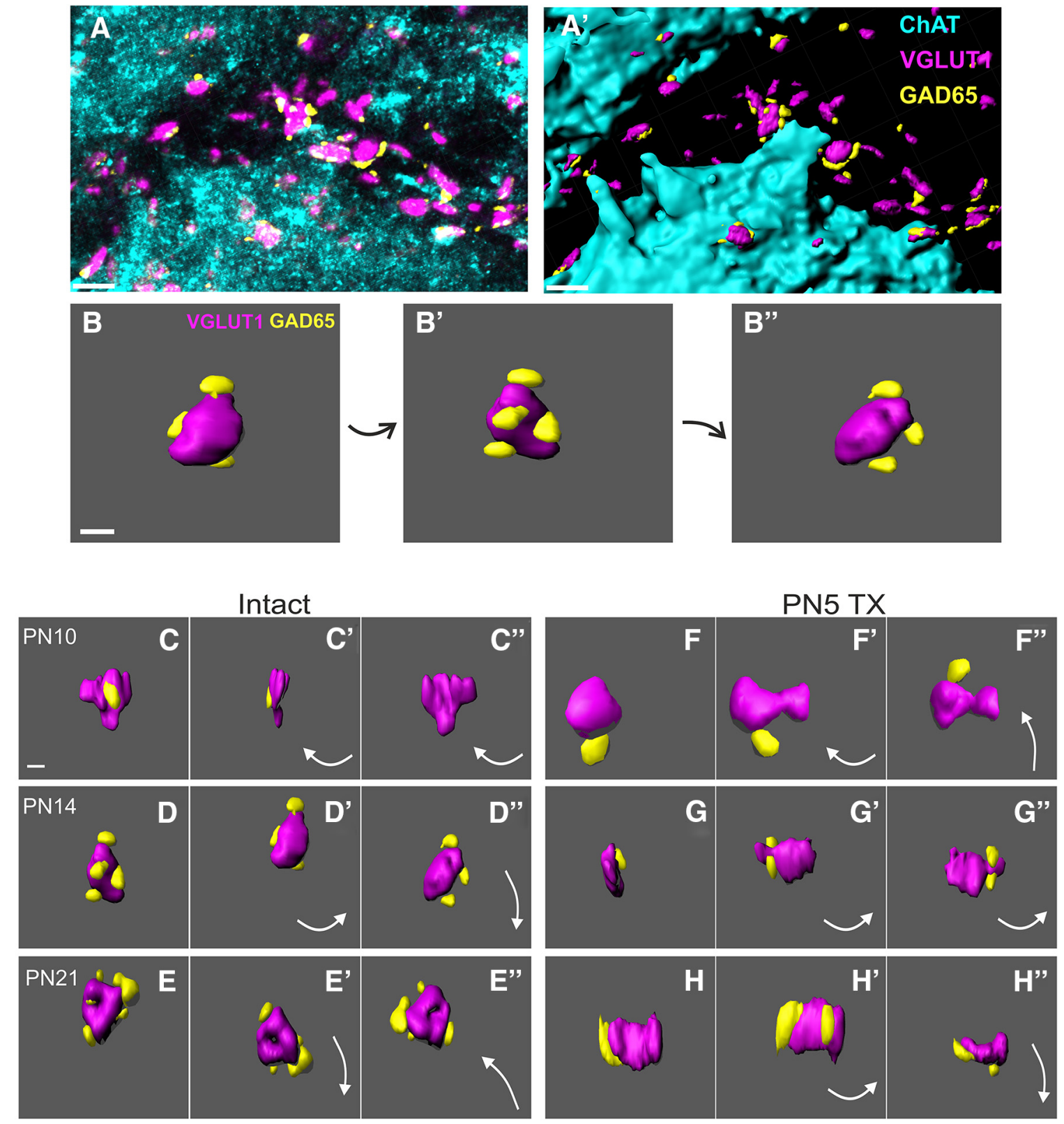

I

No. $\mathrm{P}$ boutons/ la terminal

J $\%$ la terminal with

K $\begin{gathered}\text { \% la terminal } \\ \text { devoid P boutons }\end{gathered} \quad$ Intact
$\square$ TX
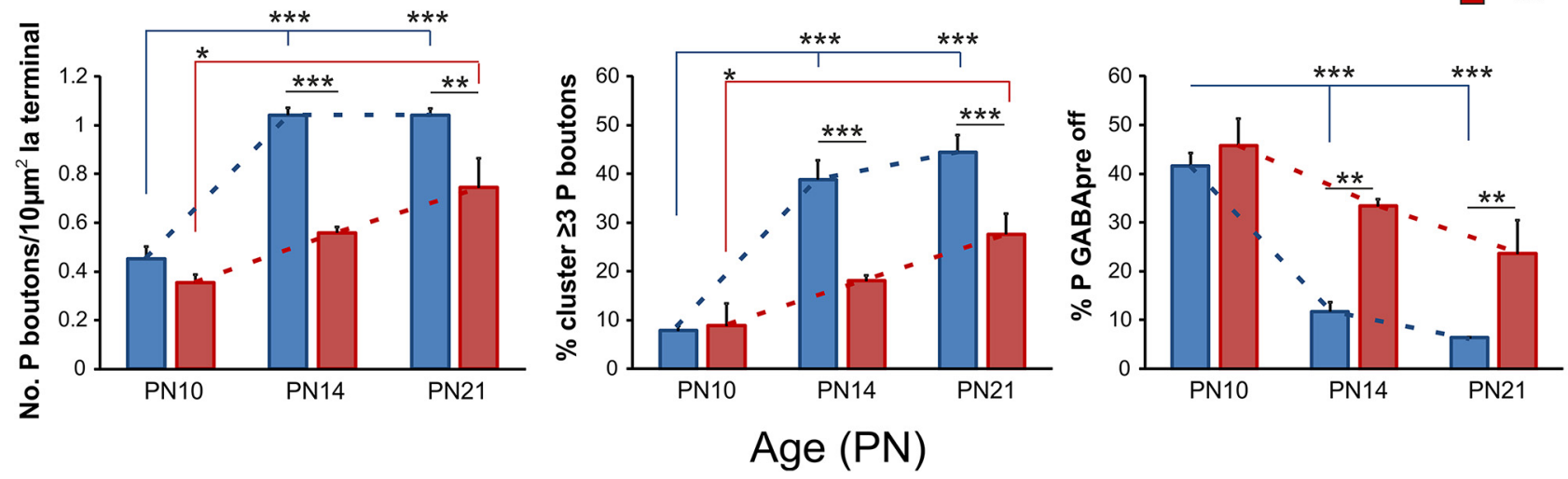

Figure 7. Postnatal development of GABApre projections in intact and P5TX rats. $\boldsymbol{A}-\boldsymbol{B}^{\prime \prime}$, IMARIS software was used to reconstruct $3 \mathrm{D}$ images of PAs contacting MNs and associated P boutons. $\boldsymbol{C}-\boldsymbol{H}^{\prime \prime}$, Representative images of P bouton contacts on PA terminals throughout postnatal development in both groups. $\boldsymbol{I} \boldsymbol{K}, \boldsymbol{Q}$, Quantification of P boutons. $\boldsymbol{I}$, Number of P boutons per $10 \mu \mathrm{m}$ of $\mathrm{PA}$ terminal surface area.J, Percentage of PA terminals with $>3$ P boutons. $K$, Percentage of PA terminals devoid of P boutons. Scale bars: $A, A^{\prime}, 5 \mu \mathrm{m} ; \boldsymbol{C}, 2 \mu \mathrm{m}$. 
structions. All PA terminals contacting MNs were analyzed (Fig. $7 A-B^{\prime \prime}$ ).

\section{GABApre projections ( $\mathrm{P}$ boutons) proliferate as PA terminals are retracted in normal development} We found that, although PAs were retracted with normal development, the density of P boutons on PA terminals increased significantly with age $(p=0.0001$; Fig. 7I). Interestingly, this increase occurred between P10 ( $0.45 \pm 0.05, n=3$; Fig. $\left.7 C-C^{\prime \prime}\right)$ and P14 (1.04 $\pm 0.03, n=3$, $p=0.0001$; Fig. $7 D-D^{\prime \prime}$ ), reaching its maximal limits between P14 and P21 $(1.04 \pm 0.03, n=3, p=0.997$; Fig. $7 E-$ $\left.E^{\prime \prime}\right)$, when the PA retraction is maximal. $\mathrm{P} 10$ and P21 were also significantly different from each other $(p=0.0001)$. At P10, $41.61 \%( \pm 2.65)$ of Ia boutons directly apposing MNs were devoid of $\mathrm{P}$ boutons; this was reduced to $11.72 \%( \pm 1.91)$ at P14 $(p=0.0001)$ and $6.37 \%( \pm 0.14)$ at $\mathrm{P} 21(p=0.0001$; Fig. $7 K)$. There was a concomitant increase $(p<0.0001)$ in the percentage of PA terminals contacted by 3 or more P boutons ( $3+$ clusters; Fig. $7 J$ ) between P10 $(7.86 \pm 0.89 \%)$ and $\mathrm{P} 14$ $(38.84 \pm 3.99 \%, p=0.0001)$ and $\mathrm{P} 21$ (44.47 $\pm 3.44 \%, p=0.0001)$, but, again, there was no change between P14 and P21 $(p=0.06)$. If the PA terminal surface area were substantially increased with age, it could be argued that PAs in younger animals have less available space for $\mathrm{P}$ boutons to contact and this could be responsible for reduced $3+$ clusters at P10. Our analysis showed that there was no change in Ia afferent terminal surface area between P10 (intact: $21.77 \pm 0.89 \mu \mathrm{m}$; TX: $20.68 \pm 1.54 \mu \mathrm{m}$ ) and P14 (intact: $22.80 \pm 0.66 \mu \mathrm{m}$; TX: $22.81 \pm 1.04 \mu \mathrm{m}$ ); however, there was an increase between P10 and P21 (intact: $26.54 \pm 0.57$ $\mu \mathrm{m} ; p=0.006$, TX: $24.90 \pm 0.85 \mu \mathrm{m}, p=0.03)$. There was no difference between intact and TX groups at any age.

\section{Neonatal transection significantly attenuates proliferation of GABApre projections to PA terminals}

The results above show that, during normal development, GABApre projections proliferate as Ia afferents are retracted. Because PA terminal density is increased after P5TX, we assessed the impact that this had on P bouton density.

We found no difference in quantity of $\mathrm{P}$ boutons closely apposing PA terminals between intact and P5TX animals at P10 (intact: $0.45 \pm 0.048$; TX: $0.36 \pm 0.032, n=3, p=0.255$; Fig. $7 C-F^{\prime}$ ), just as we saw no difference in PA density at this stage. In contrast, there were significantly fewer P boutons in the TX group at P14 (intact: $1.04 \pm 0.03$; TX: $0.56 \pm 0.02, n=3, p=0.001$; Fig. $7 D-G^{\prime \prime}$ ) and P21 (intact: $1.04 \pm 0.03$; TX: $0.75 \pm 0.12, n=3, p=$ 0.004; Fig. $7 E-H^{\prime \prime}$ ). This was due to a greater proportion of PA terminals devoid of P boutons at P14 (intact: $11.79 \pm 1.95 \%$; TX: $33.36 \pm 1.42 \%, p=0.002$ ) and P21 (intact: $6.37 \pm 0.14 \%$; TX: $23.61 \pm 6.91 \%, p=0.008)$. Similarly, PA terminals apposed by clusters of $>3 \mathrm{P}$ boutons were also reduced at these ages (P14 intact: $38.84 \pm 3.99 \%$; TX: $18.10 \pm 1.03 \%, p=0.001$; P21 intact: $44.47 \pm 3.45 \%$; TX: $27.61 \pm 4.22 \%, p=0.001)$. It is important to note, however, that, despite this attenuation, there was still a significant increase in $\mathrm{P}$ bouton density in the P5 TX group between P10 and P21 (P10: $0.36 \pm 0.03$; P21: $0.75 \pm 0.12, p=0.001$ ).

In summary, our analyses show that, as PA terminals are retracted during normal development, GABApre projections proliferate. This profile is severely, but not completely, attenuated by P5TX (Fig. 8).

\section{Hyperexcitability of the monosynaptic reflex after neonatal transection}

Our anatomical data show reduced retraction of afferents, reduced modulatory input from GABApre neurons, and reduced motor axon input to RCs, collectively suggesting that development in the absence of descending systems induces hyperexcitability of the lumbar sensorimotor circuitry. We tested this hypothesis by assessing $\mathrm{H}$ reflexes in a perfused whole-rat preparation that is viable throughout postnatal development (first described by Pickering and Paton, 2006). The development of this preparation was vital to the success of these experiments. The decerebration was necessary to negate the variable effects of anesthetics such as ketamine on the developing CNS. In addition, the low blood volume of neonates means hemorrhaging upon severance of major vessels (as occurs with decerebration) leads rapidly to hypovolemic death. Our perfused preparation allowed full control of the systemic volume, pressure, and oxygenation levels and, as a result, greater success rates without the need for anesthesia.

Interestingly, we were not able to evoke $\mathrm{H}$ reflexes at $\mathrm{P} 10 . \mathrm{H}$ reflexes were also absent at this age in ketamine-anesthetized rats (data not shown). H reflex amplitudes, thresholds, and interactions did not vary greatly between P14 and P21 in intact or TX groups, so these data were pooled. Therefore, $\mathrm{H}$ reflexes were 

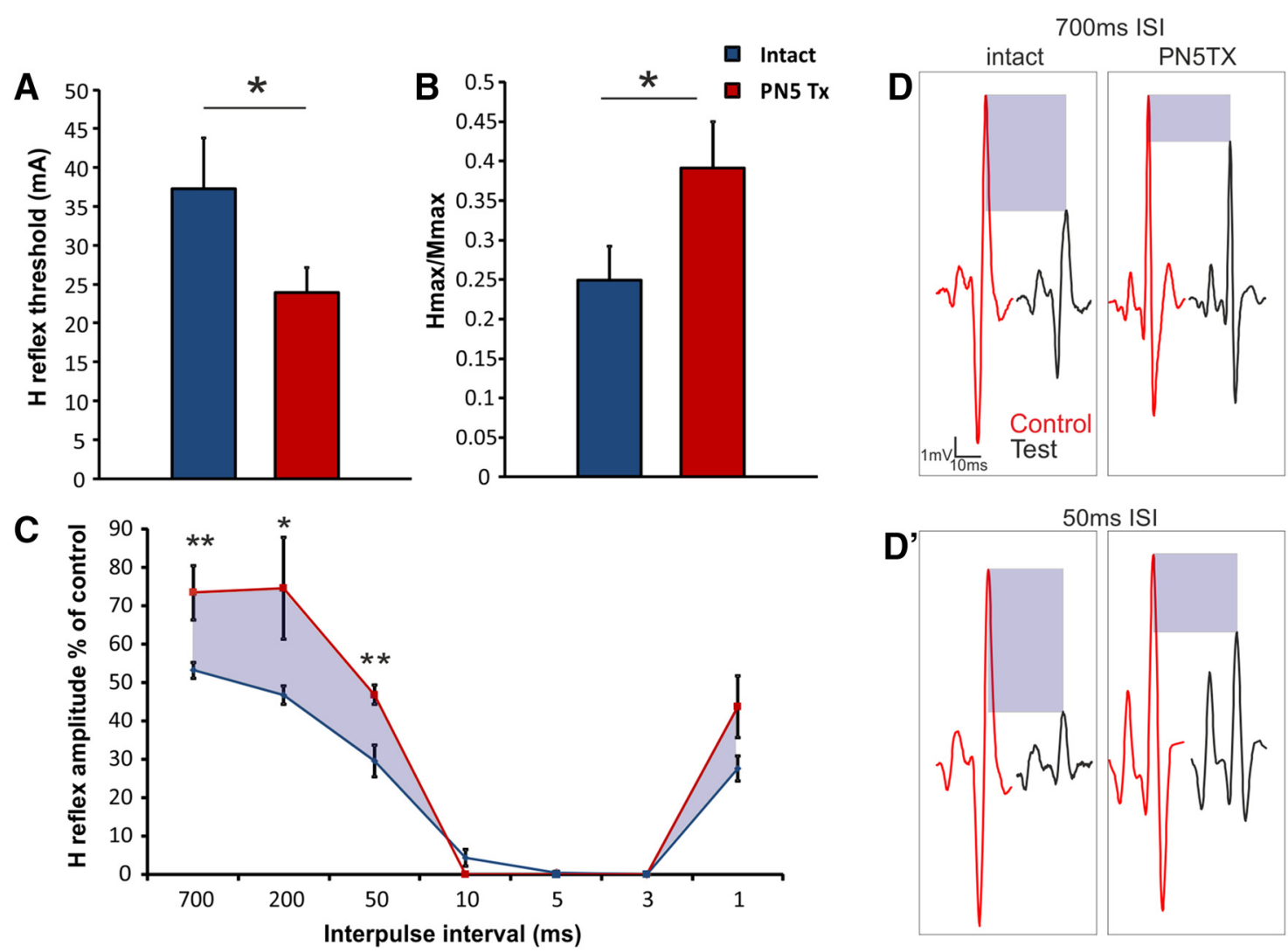

Figure 9. Monosynaptic reflex excitability of intact and neonatally transected rats. $\boldsymbol{A}, \boldsymbol{B}, \mathrm{H}$ reflex threshold is reduced and $H_{\max } / M_{\text {max }}$ ratio is increased in P14 $-\mathrm{P} 21$ rats after neonatal transection. C, Paired-pulse depression of the $\mathrm{H}$ reflex in intact and neonatally transected rats at P14-P21. Shaded areas highlight the difference in $\mathrm{H}$ wave inhibition between intact and P5TX rats. $\boldsymbol{D}$, $\boldsymbol{D}^{\prime}$, Representative traces from intact and P5TX rats at long (700 ms) and short (50 ms) time intervals.

assessed between intact and P5TX rats aged P14-P21. Thresholding revealed that the excitability of the monosynaptic reflex was increased in P5TX animals due to lower thresholds for evoking $\mathrm{H}$ reflex responses (intact: $37.3 \pm 6.6 \mathrm{~mA}, n=6$; TX: $23.9 \pm 3.2 \mathrm{~mA}$, $p=0.050, n=7$; Fig. 9A). Similarly, P5TX resulted in a significantly greater $H_{\max } / M_{\max }$ ratio (intact: $0.25 \pm 0.04 \mathrm{mV}, n=5$; TX: $0.39 \pm 3.21 \mathrm{mV}, n=4, p=0.046$; Fig. $9 B$ ). There were no significant differences between groups in $\mathrm{H}$ reflex latency. For assessing homonymous paired-pulse inhibition between groups, we used 7 interpulse intervals from 700 to $1 \mathrm{~ms}$. The evoked $\mathrm{H}$ reflex response was extremely low at intervals between 10 and 1 ms, presumably due to axonal collisions. There were significant differences, however, at intervals 700 to $50 \mathrm{~ms}$ and an overall effect of P5TX on paired pulse depression. At each time interval, P5TX animals displayed significantly attenuated PPD, resulting in test responses with greater amplitudes represented as a percentage of the control (single pulse) compared with intact animals (700 ms intact: $53.24 \pm 2.07 \%, n=4$, TX: $73.47 \pm 7.12 \%$, $n=3 ; p=0.026 ; 200 \mathrm{~ms}$ intact: $46.80 \pm 2.32 \%, n=6$, TX: $74.62 \pm 13.33 \%, n=4, p=0.001 ; 50 \mathrm{~ms}$ intact: $29.64 \pm 4.14 \%$, $n=6$, TX: $46.81 \pm 4.14, n=4, p=0.040$; Fig. $\left.9 C, D^{\prime}\right)$.

\section{Discussion}

This study demonstrates that neonatal transection precludes normal development of spinal sensorimotor circuits (Fig. 10). We show postnatal retraction of VGLUT1 ${ }^{+}$boutons from dorsal, intermediate, and ventral regions of the lumbar cord, which is completely absent after TX. Importantly, TX also induced malformation of key modulatory microcircuits responsible for presynaptic inhibition of afferents and recurrent inhibition, leading to hyperexcitability of the $\mathrm{H}$ reflex in maturity. Therefore, we not only characterize important features of spinal circuit development, but also highlight mechanisms contributing to motor dysfunction in conditions such as CP and spinal cord injury (SCI).

Developmental retraction of afferents from the lumbar spinal cord is dependent upon the presence of descending systems

Postnatal development of PAs in the cervical spinal cord has been well studied in the rat and cat, but the functionally different lumbar segments have never been assessed. Gibson and Clowry (1999) showed retraction of PAs from the ventral horn during development of the rat cervical spinal cord, whereas Chakrabarty and Martin (2011a) identified refinement of PAs in dorsal and intermediate regions of the cat cervical spinal cord. We show that, early postnatally, when locomotion is immature, PA input to lumbar MNs is dense but subsequently retracted as locomotion becomes mature (P14-P21). At the same time points, retraction of $\mathrm{VGLUT} 1^{+}$puncta was also seen in dorsal and intermediate regions as well as on RCs. It is important to note, however, that Siembab et al. (2016) showed that not all interneuron populations are subject to PA retraction. In addition, development of cutaneous fibers in dorsal and intermediate regions (Fitzgerald, 2005) may have contributed to VGLUT1 retraction.

Our results showing retraction of PAs from RCs is consistent with previous work demonstrating that PAs innervate and activate RCs early postnatally, but inputs in adulthood are greatly reduced and not capable of activation (Renshaw, 1946; Eccles et al., 1957; Mentis et al., 2006).

The mechanisms responsible for afferent pruning during development of the cervical spinal cord are not fully understood, 

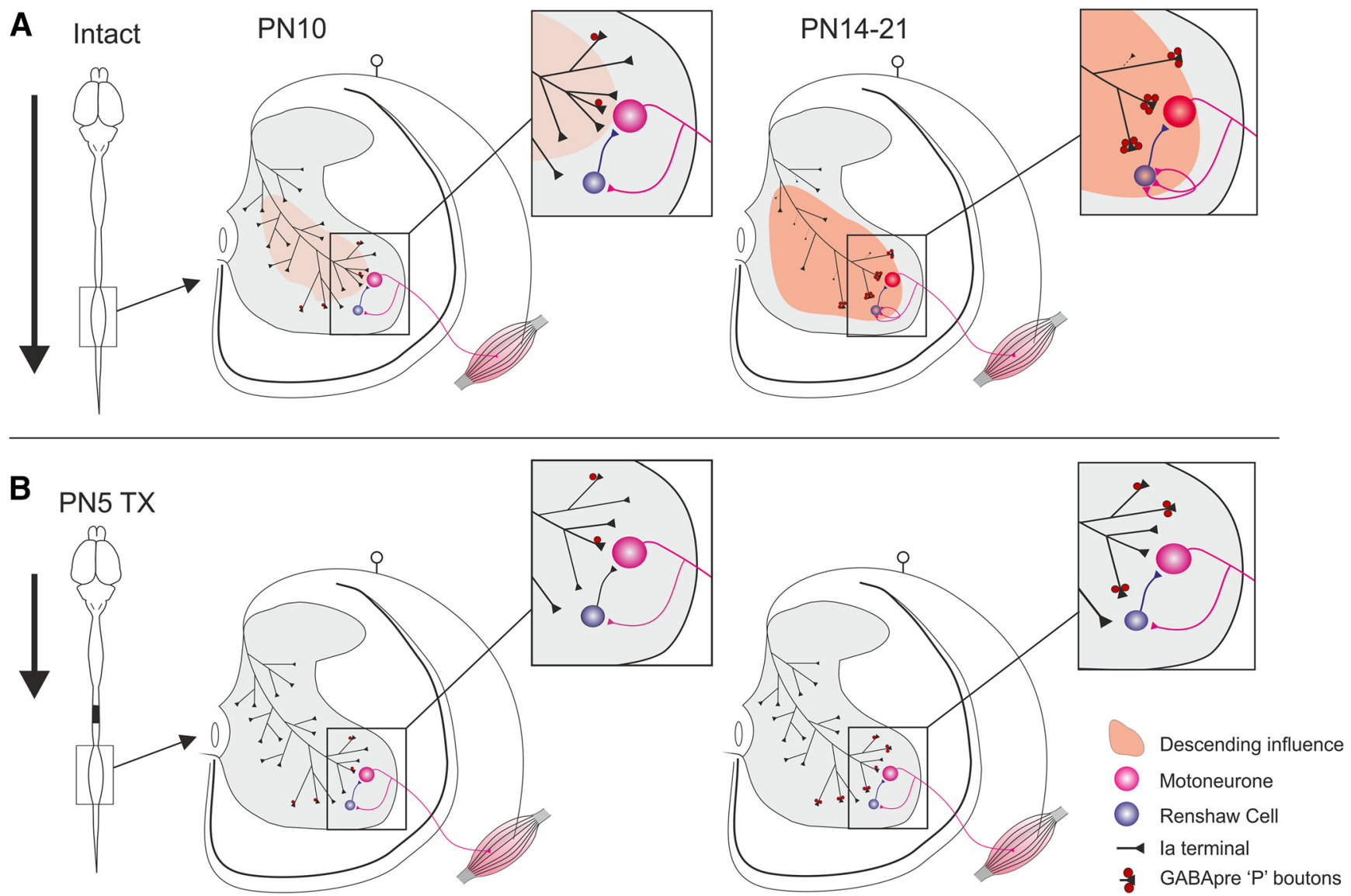

Figure 10. Schematic summarizing the postnatal development of the lumbar spinal sensorimotor circuitry in intact and neonatally transected rats. $\boldsymbol{A}$, Intact development. $\boldsymbol{B}$, Development after neonatal transection.

but thought to be related to competition with descending systems (Gibson et al., 2000; Clowry et al., 2004; Martin, 2005; Clowry, 2007; Chakrabarty and Martin, 2011b). An important consideration here is that cervical motor circuits control muscles responsible for reaching and grasping, which require fine control of forelimb muscles and are therefore critically dependent upon interactions between descending and sensory systems (Alstermark and Isa, 2012). The lumbar spinal cord is less associated with fine motor control and therefore may not develop in the same manner. Despite these functional differences between cervical and lumbar cords, we found that lumbar PA development is affected similarly to what has been described previously for cervical PAs after altering descending inputs.

\section{Neonatal transection prevents postnatal retraction of proprioceptive afferents}

In contrast to normal development, we show that, in P5TX rats, PAs fail to retract. The physiological manifestation of this anatomical finding was reduced $\mathrm{H}$ reflex thresholds compared with intact counterparts.

It is known that afferent sprouting in mature spinal cords can be induced by lesions to descending tracts or supraspinal regions (Liu and Chambers, 1958; Nelson and Mendell, 1979; Krenz and Weaver, 1998; Tan et al., 2012). However, the mechanisms leading to increased afferent input after neonatal lesions may be different. Adult injuries are sustained when lumbar spinal circuits are fully mature, having been organized under the influence of both descending and sensory input. When the same injury is sustained neonatally, locomotor circuits are immature and sub- sequently develop in the presence of sensory input alone. Considering that we show PA retraction during normal development, it is likely that, after P5TX, afferents fail to retract rather than sprout. This is consistent with the work of Levinsson et al. (1999), who found that neonatal transection in rats results in immature nociceptive reflexes in adulthood. Therefore, it is reasonable to suggest that descending input to the lumbar cord is necessary for normal development of sensorimotor systems. Indeed, the CST does not innervate the lumbar cord until P8-P9, meaning that it has no influence on spinal circuit development in P5TX rats (Donatelle, 1977). Furthermore, brainstem projections are present in the lumbar cord early postnatally, but do not mature until the end of the second postnatal week and thus also have little influence on spinal circuit development in P5TX rats (Bregman, 1987; Vinay et al., 2005). It could be argued that brainstem systems have greater influence on developmental input of PAs to ventral motor circuits because CST lacks direct functional connections here (Alstermark et al., 2004). Indeed, Basaldella et al. (2015) showed recently that genetically reducing vestibular sensation using Nox3 mutant mice lead to greater densities of VGLUT1 ${ }^{+}$ boutons on MNs.

Alternatively, a lack of retraction may have resulted from homeostatic mechanisms serving to maintain functional levels of excitability after P5TX. In support of this hypothesis, Mendelsohn et al. (2015) showed that significantly reducing sensory-motor synaptic transmission without affecting input density resulted in sprouting of afferent collaterals onto synergistic, heteronymous motoneurons. This, combined with other recent literature, sug- 
gests that the development of PA projection densities is mediated by a combination of activity, positional cues, and recognition signals (Sürmeli et al., 2011; Bikoff et al., 2016). However, further work is needed to understand these mechanisms in the context of spasticity in conditions such as CP and SCI.

\section{Neonatal transection disrupts formation of the Renshaw cell-motoneuron circuit}

Renshaw cells modulate motor output by forming a remarkably efficient recurrent inhibitory circuit with MNs (Bhumbra et al., 2014; Moore et al., 2015). During normal development, both motor axon and PA synapses proliferate on RCs up to P15, after which PA terminals retract (Mentis et al., 2006). Siembab et al., 2016 showed recently that genetically upscaling or downscaling proprioceptive inputs to RCs significantly regulated the development of motor axon input density. In our study, PA input to RCs was increased as a result of P5TX. In agreement with Siembab et al. (2016), between P14 and P21, motor axon synapses on RCs were severely reduced after TX, suggesting that similar mechanisms are involved. The fact that there was no difference in PA input between intact and P5TX animals at P21 suggests that retraction from RCs was restored. Therefore, considering the loss of motor axon input between P14 and P21, RCs experience a significant developmental loss of excitatory input after P5TX, which could be an important determinant of spasticity in our model and CP.

\section{Neonatal transection severely disrupts development of GABApre neuron projections.}

Accurate control of movement depends on the gating and directing of sensory information in the spinal cord. This control is mediated by GABApre interneurons exerting presynaptic inhibition via axo-axonic projections ( $\mathrm{P}$ boutons) to sensory terminals (Frank and Fuortes, 1957; Eccles et al., 1961; Hughes et al., 2005; Rudomin, 2009). Neonatal animals often display poorly directed, exaggerated responses to sensory stimuli (Weed, 1917; Stelzner, 1971), which are attenuated with postnatal development, suggesting refinement of afferent projections and/or their modulation. Although postnatal afferent retraction has been demonstrated, development of axo-axonic GABApre contacts on sensory terminals is not understood. In adult cats, Pierce and Mendell (1993) showed that $86 \%$ of Ia terminals have $\mathrm{P}$ boutons, but it is not known when this profile is established. Betley et al. (2009) demonstrated that GABApre projections express stringent specificity for sensory terminals, shunning MNs even when PA terminations were genetically reduced using Er81 ${ }^{-1-}$ mutant mice. Further, the lack of available targets resulted in significant retraction of GABApre projections from the ventral horn. Our data show codevelopment of PA terminals and $\mathrm{P}$ boutons, with both reaching a plateau with motor maturity (P14-P21). However, P bouton density significantly increased as PA terminals were retracted, showing an inverse rather than direct relationship (Fig. 7). Between P10 (41.61\%) and P21 (6.37\%), there was a $35.24 \%$ decrease in PA terminals lacking $\mathrm{P}$ boutons, indicating that the increase is due to greater GABApre projections to PAs, rather than a redistribution of $\mathrm{P}$ boutons from retracted PA terminals. This suggests that regulation of GABApre projections cannot be governed solely by local spinal mechanisms. Indeed, adult sacral spinal cord TX also results in $\mathrm{P}$ bouton retraction, even though PA terminal density remains unchanged (Kapitza et al., 2012).

After P5TX in our study, $\mathrm{P}$ boutons apposing PA terminals were severely reduced, but these axo-axonic contacts still proliferated with development. Interestingly, Mende et al. (2016) showed that the efficacy of presynaptic inhibition can be regulated by local glutamate signaling between sensory terminals and P boutons. Reducing VGLUT1 availability led to reduced presynaptic inhibition via downregulation of GAD65/67 in GABApre boutons. Given the high PA input and reduced paired pulse depression seen in our study, similar mechanisms may be responsible for the developmental increase in $\mathrm{P}$ bouton density despite P5TX.

Our findings contribute detail and depth toward comprehension of postnatal sensorimotor circuit formation. Although the core locomotor circuitry is functional prenatally, acquisition of mature organization, and therefore behavior, depends on postnatal integration of descending systems. By removing descending input early postnatally, the development of key spinal sensorimotor circuits is severely disrupted, leading to hyperreflexia. Similar mechanisms have been shown previously to contribute to spasticity in adult injuries; however, direct comparisons with neonatal injuries will be needed to identify differences and similarities. It is likely that, after neonatal injuries, the same circuits contributing to spasticity may also contribute to enhanced functional recovery, so it is crucial that we target these circuits to better understand and treat perinatal and adult lesions to descending systems.

\section{References}

Alstermark B, Isa T (2012) Circuits for skilled reaching and grasping. Annu Rev Neurosci 35:559-578. CrossRef Medline

Alstermark B, Ogawa J, Isa T (2004) Lack of monosynaptic corticomotoneuronal EPSPs in rats: disynaptic EPSPs mediated via reticulospinal neurons and polysynaptic EPSPs via segmental interneurons. J Neurophysiol 91:1832-1839. CrossRef Medline

Altman J, Sudarshan K (1975) Postnatal development of locomotion in the laboratory rat. Anim Behav 23:896-920. CrossRef Medline

Alvarez FJ, Villalba RM, Zerda R, Schneider SP (2004) Vesicular glutamate transporters in the spinal cord, with special reference to sensory primary afferent synapses. J Comp Neurol 472:257-280. CrossRef Medline

Basaldella E, Takeoka A, Sigrist M, Arber S (2015) Multisensory signaling shapes vestibulo-motor circuit specificity. Cell 163:301-312. CrossRef Medline

Betley JN, Wright CV, Kawaguchi Y, Erdélyi F, Szabó G, Jessell TM, Kaltschmidt JA (2009) Stringent specificity in the construction of a GABAergic presynaptic inhibitory circuit. Cell 139:161-174. CrossRef Medline

Bhumbra GS, Bannatyne BA, Watanabe M, Todd AJ, Maxwell DJ, Beato M (2014) The recurrent case for the Renshaw cell. J Neurosci 34:1291912932. CrossRef Medline

Bikoff JB, Gabitto MI, Rivard AF, Drobac E, Machado TA, Miri A, BrennerMorton S, Famojure E, Diaz C, Alvarez FJ, Mentis GZ, Jessell TM (2016) Spinal inhibitory interneuron diversity delineates variant motor microcircuits. Cell 165:207-219. CrossRef Medline

Bregman BS (1987) Development of serotonin immunoreactivity in the rat spinal cord and its plasticity after neonatal spinal cord lesions. Brain Res 431:245-263. CrossRef Medline

Brocard F, Vinay L, Clarac F (1999) Development of hindlimb postural control during the first postnatal week in the rat. Brain Res Dev Brain Res 117:81-89. CrossRef Medline

Bui TV, Stifani N, Akay T, Brownstone RM (2016) Spinal microcircuits comprising $\mathrm{dI} 3$ interneurons are necessary for motor functional recovery following spinal cord transection. eLife 5:e21715. CrossRef Medline

Cazalets JR, Menard I, Crémieux J, Clarac F (1990) Variability as a characteristic of immature motor systems: an electromyographic study of swimming in the newborn rat. Behav Brain Res 40:215-225. CrossRef Medline

Chakrabarty S, Martin J (2011a) Postnatal refinement of proprioceptive afferents in the cat cervical spinal cord. Eur J Neurosci 33:1656-1666. CrossRef Medline

Chakrabarty S, Martin JH (2011b) Co-development of proprioceptive afferents and the corticospinal tract within the cervical spinal cord. Eur J Neurosci 34:682-694. CrossRef Medline 
Chen HH, Hippenmeyer S, Arber S, Frank E (2003) Development of the monosynaptic stretch reflex circuit. Curr Opin Neurobiol 13:96-102. CrossRef Medline

Clowry GJ (2007) The dependence of spinal cord development on corticospinal input and its significance in understanding and treating spastic cerebral palsy. Neurosci Biobehav Rev 31:1114-1124. CrossRef Medline

Clowry GJ, Davies BM, Upile NS, Gibson CL, Bradley PM (2004) Spinal cord plasticity in response to unilateral inhibition of the rat motor cortex during development: changes to gene expression, muscle afferents and the ipsilateral corticospinal projection. Eur J Neurosci 20: 2555-2566. CrossRef Medline

Commissiong JW, Toffano G (1989) Complete spinal cord transection at different postnatal ages: recovery of motor coordination correlated with spinal cord catecholamines. Exp Brain Res 78:597-603. Medline

DietzV, Sinkjaer T (2007) Spastic movement disorder: impaired reflex function and altered muscle mechanics. Lancet Neurol 6:725-733. CrossRef Medline

Donatelle JM (1977) Growth of the corticospinal tract and the development of placing reactions in the postnatal rat. J Comp Neurol 175:207-231. CrossRef Medline

Du Beau A, Shakya Shrestha S, Bannatyne BA, Jalicy SM, Linnen S, Maxwell DJ (2012) Neurotransmitter phenotypes of descending systems in the rat lumbar spinal cord. Neuroscience 227:67-79. CrossRef Medline

Eccles JC, Eccles RM, Lundberg A (1957) The convergence of monosynaptic excitatory afferents on to many different species of alpha motoneurons. J Physiol 137:22-50. CrossRef Medline

Eccles J, Eccles RM, Magni F (1961) Central inhibitory action attributable to presynaptic depolarization produced by muscle afferent volleys. J Physiol 159:147-166. CrossRef Medline

Fitzgerald M (2005) The development of nociceptive circuits. Nat Rev Neurosci 6:507-520. Medline

Frank K, Fortes MGF (1957) Presynaptic and postsynaptic inhibition of monosynaptic reflexes. Fed Proc 16:39-40.

Fukuhara K, Imai F, Ladle DR, Katayama K, Leslie JR, Arber S, Jessell TM, Yoshida Y (2013) Specificity of monosynaptic sensory-motor connections imposed by repellent Sema3E-PlexinD1 signaling. Cell Rep 5:748758. CrossRef Medline

Gibson CL, Clowry GJ (1999) Retraction of muscle afferents from the rat ventral horn during development. Neuroreport 10:231-235. CrossRef Medline

Gibson CL, Arnott GA, Clowry GJ (2000) Plasticity in the rat spinal cord seen in response to lesions to the motor cortex during development but not to lesions in maturity. Exp Neurol 166:422-434. CrossRef Medline

Hughes DI, Mackie M, Nagy GG, Riddell JS, Maxwell DJ, Szabó G, Erdélyi F, Veress G, Szucs P, Antal M, Todd AJ (2005) P boutons in lamina IX of the rodent spinal cord express high levels of glutamic acid decarboxylase- 65 and originate from cells in deep medial dorsal horn. Proc Natl Acad Sci U S A 102:9038-9043. CrossRef Medline

Ichiyama RM, Broman J, Edgerton VR, Havton LA (2006) Ultrastructural synaptic features differ between $\alpha$-and $\gamma$-motoneurons innervating the tibialis anterior muscle in the rat. J Comp Neurol 499:306-315. CrossRef Medline

Ichiyama RM, Broman J, Roy RR, Zhong H, Edgerton VR, Havton LA (2011) Locomotor training maintains normal inhibitory influence on both alpha-and gamma-motoneurons after neonatal spinal cord transection. J Neurosci 31:26-33. CrossRef Medline

Joosten EA, Gribnau AA, Dederen PJ (1989) Postnatal development of the corticospinal tract in the rat. Anat Embryol 179:449-456. CrossRef Medline

Kapitza S, Zörner B, Weinmann O, Bolliger M, Filli L, Dietz V, Schwab ME (2012) Tail spasms in rat spinal cord injury: changes in interneuronal connectivity. Exp Neurol 236:179-189. CrossRef Medline

Krenz NR, Weaver LC (1998) Sprouting of primary afferent fibers after spinal cord transection in the rat. Neuroscience 85:443-458. CrossRef Medline

Kudo N, Yamada T (1985) Development of the monosynaptic stretch reflex in the rat: an in vitro study. J Physiol 369:127-144. CrossRef Medline

Levinsson A, Luo XL, Holmberg H, Schouenborg J (1999) Developmental tuning in a spinal nociceptive system: effects of neonatal spinalization. J Neurosci 19:10397-10403. Medline

Liu CN, Chambers W (1958) Intraspinal sprouting of dorsal root axons: development of new collaterals and preterminals following partial denervation of the spinal cord in the cat. AMA Arch Neurol Psychiatry 79:46-61. CrossRef Medline

Martin JH (2005) The corticospinal system: from development to motor control. Neuroscientist 11:161-173. CrossRef Medline

Mears SC, Frank E (1997) Formation of specific monosynaptic connections between muscle spindle afferents and motoneurons in the mouse. J Neurosci 17:3128-3135. Medline

Mendelsohn AI, Simon CM, Abbott LF, Mentis GZ, Jessell TM (2015) Activity regulates the incidence of heteronymous sensory-motor connections. Neuron 87:111-123. CrossRef Medline

Mende M, Fletcher EV, Belluardo JL, Pierce JP, Bommareddy PK, Weinrich JA, Kabir ZD, Schierberl KC, Pagiazitis JG, Mendelsohn AI, Francesconi A, Edwards RH, Milner TA, Rajadhyaksha AM, van Roessel PJ, Mentis GZ, Kaltschmidt JA (2016) Sensory-derived glutamate regulates presynaptic inhibitory terminals in mouse spinal cord. Neuron 90:1189-1202. CrossRef Medline

Mentis GZ, Siembab VC, Zerda R, O’Donovan MJ, Alvarez FJ (2006) Primary afferent synapses on developing and adult Renshaw cells. J Neurosci 26:13297-13310. CrossRef Medline

Moore NJ, Bhumbra GS, Foster JD, Beato M (2015) Synaptic connectivity between Renshaw cells and motoneurons in the recurrent inhibitory circuit of the spinal cord. J Neurosci 35:13673-13686. CrossRef Medline

Nelson SG, Mendell LM (1979) Enhancement in Ia-motoneuron synaptic transmission caudal to chronic spinal cord transection. J Neurophysiol 42:642-654. Medline

Ozaki S, Yamada T, Iizuka M, Nishimaru H, Kudo N (1996) Development of locomotor activity induced by NMDA receptor activation in the lumbar spinal cord of the rat fetus studied in vitro. Brain Res Dev Brain Res 97:118-125. CrossRef Medline

Petruska JC, Ichiyama RM, Jindrich DL, Crown ED, Tansey KE, Roy RR, Edgerton VR, Mendell LM (2007) Changes in motoneuron properties and synaptic inputs related to step training after spinal cord transection in rats. J Neurosci 27:4460-4471. CrossRef Medline

Pickering AE, Paton JF (2006) A decerebrate, artificially-perfused in situ preparation of rat: utility for the study of autonomic and nociceptive processing. J Neurosci Methods 155:260-271. CrossRef Medline

Pierce JP, Mendell LM (1993) Quantitative ultrastructure of Ia boutons in the ventral horn: scaling and positional relationships. J Neurosci 13: 4748-4763. Medline

Renshaw B (1946) Central effects of centripetal impulses in axons of spinal ventral roots. J Neurophysiol 9:191-204. Medline

Rosenbaum P, Eliasson AC, Hidecker MJ, Palisano RJ (2014) Classification in childhood disability focusing on function in the 21st century. J Child Neurol 29:1036-1045. CrossRef Medline

Rudomin P (2009) In search of lost presynaptic inhibition. Exp Brain Res 196:139-151. CrossRef Medline

Saunders NR, Kitchener P, Knott GW, Nicholls JG, Potter A, Smith TJ (1998) Development of walking, swimming and neuronal connections after complete spinal cord transection in the neonatal opossum, Monodelphis domestica. J Neurosci 18:339-355. Medline

Siembab VC, Gomez-Perez L, Rotterman TM, Shneider NA, Alvarez FJ (2016) Role of primary afferents in the developmental regulation of motor axon synapse numbers on Renshaw cells. J Comp Neurol 524:18921919. CrossRef Medline

Stelzner DJ (1971) The normal postnatal development of synaptic end-feet in the lumbosacral spinal cord and of responses in the hind limbs of the albino rat. Exp Neurol 31:337-357. CrossRef Medline

Sürmeli G, Akay T, Ippolito GC, Tucker PW, Jessell TM (2011) Patterns of spinal sensory-motor connectivity prescribed by a dorsoventral positional template. Cell 147:653-665. CrossRef Medline

Tan AM, Chakrabarty S, Kimura H, Martin JH (2012) Selective corticospinal tract injury in the rat induces primary afferent fiber sprouting in the spinal cord and hyperreflexia. J Neurosci 32:12896-12908. CrossRef Medline

Tillakaratne NJ, Guu JJ, de Leon RD, Bigbee AJ, London NJ, Zhong H, Ziegler MD, Joynes RL, Roy RR, Edgerton VR (2010) Functional recovery of stepping in rats after a complete neonatal spinal cord transection is not due to regrowth across the lesion site. Neuroscience 166:23-33. CrossRef Medline

Todd AJ, Hughes DI, Polgár E, Nagy GG, Mackie M, Ottersen OP, Maxwell DJ (2003) The expression of vesicular glutamate transporters VGLUT1 and 
VGLUT2 in neurochemically defined axonal populations in the rat spinal cord with emphasis on the dorsal horn. Eur J Neurosci 17:13-27. CrossRef Medline

Van Hartesveldt C, Sickles AE, Porter JD, Stehouwer DJ (1991) L-DOPAinduced air-stepping in developing rats. Brain Res Dev Brain Res 58:251255. CrossRef Medline

Varoqui H, Schäfer MK, Zhu H, Weihe E, Erickson JD (2002) Identification of the differentiation-associated $\mathrm{Na}+/ \mathrm{PI}$ transporter as a novel vesicular glutamate transporter expressed in a distinct set of glutamatergic synapses. J Neurosci 22:142-155. Medline

Vinay L, Ben-Mabrouk F, Brocard F, Clarac F, Jean-Xavier C, Pearlstein E, Pflieger JF (2005) Perinatal development of the motor systems in- volved in postural control. Neural Plast 12:131-139; discussion 263 272. CrossRef Medline

Weber ED, Stelzner DJ (1977) Behavioral effects of spinal cord transection in the developing rat. Brain Res 125:241-255. CrossRef Medline

Weed LH (1917) The reactions of kittens after decerebration. Am J Physiol 43:131-157

Westerga J, Gramsbergen A (1993a) Changes in the electromyogram of two major hindlimb muscles during locomotor development in the rat. Exp Brain Res 92:479-488. Medline

Westerga J, Gramsbergen A (1993b) Development of locomotion in the rat: the significance of early movements. Early Hum Dev 34:89-100. CrossRef Medline 